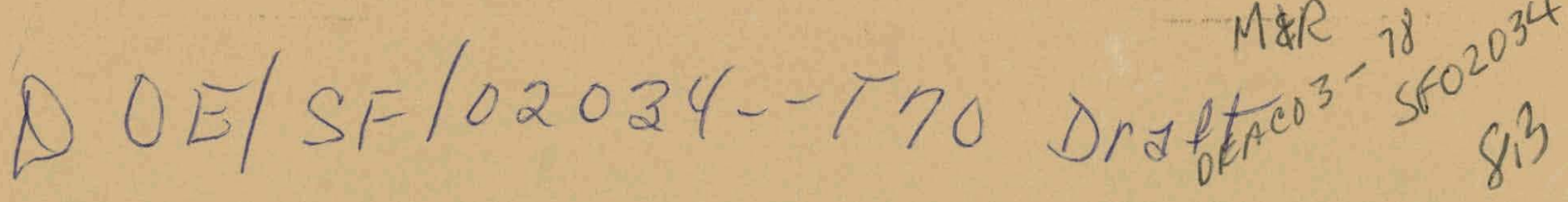

$$
\begin{aligned}
& 82-125531
\end{aligned}
$$

Draft Report

\title{
HIGH-TEMPERATURE GAS-COOLED REACTOR SAFETY-RELIABILITY PROGRAM PLAN
}

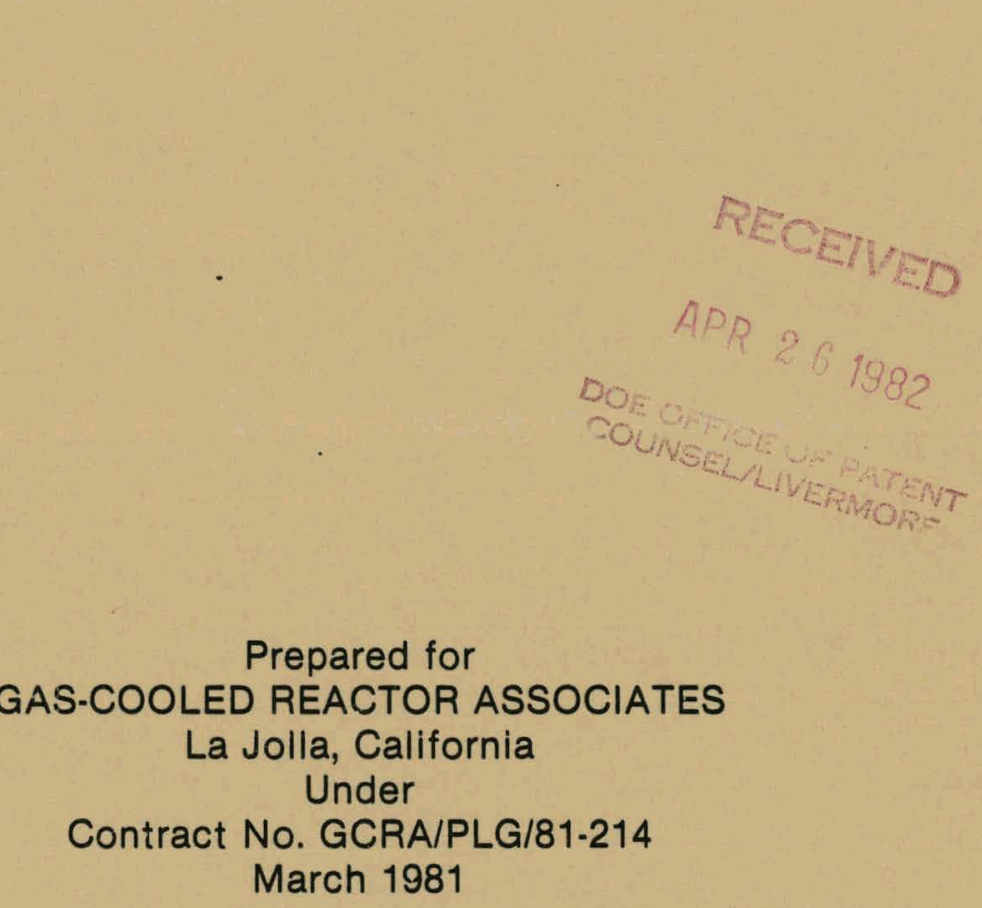




\section{DISCLAIMER}

This report was prepared as an account of work sponsored by an agency of the United States Government. Neither the United States Government nor any agency Thereof, nor any of their employees, makes any warranty, express or implied, or assumes any legal liability or responsibility for the accuracy, completeness, or usefulness of any information, apparatus, product, or process disclosed, or represents that its use would not infringe privately owned rights. Reference herein to any specific commercial product, process, or service by trade name, trademark, manufacturer, or otherwise does not necessarily constitute or imply its endorsement, recommendation, or favoring by the United States Government or any agency thereof. The views and opinions of authors expressed herein do not necessarily state or reflect those of the United States Government or any agency thereof. 


\section{DISCLAIMER}

Portions of this document may be illegible in electronic image products. Images are produced from the best available original document. 
PLG-0163

DOE/SE/02034--T70-DRAF"

DE82 007242

\title{
HIGH-TEMPERATURE GAS-COOLED REACTOR SAFETY-RELIABILITY PROGRAM PLAN
}

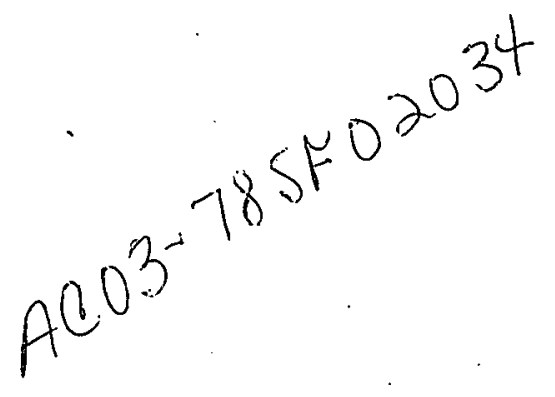$$
9511841
$$ \\ Prepared for \\ GAS-COOLED REACTOR ASSOCIATES \\ La Jolla, California \\ Under \\ Contract No. GCRA/PLG/81-214 \\ March 1981
}

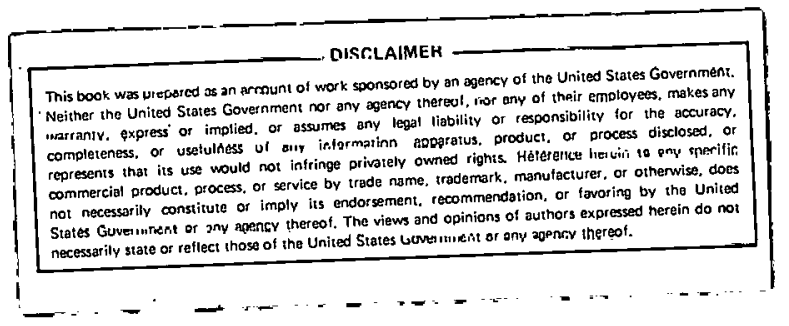

DISTRBBUTION OF IHIS ROCUAEEAT IS UNLIMUTEO

\author{
PICKARD, LOWE AND GARRICK, INC. \\ CONSULTANTS - ELECTRIC POWER \\ IRVINE, CALIFORNIA \\ WASHINGTON, D.C.
}


Section

$\underline{\text { Page }}$

1 INTRODUCT ION

1.1 Purpose

1.2 Scope

1.3 Background

1.3.1 Licensing Requirements

1.3.2 HTGR Licensing History

1.3.3 Probabilistic Risk Assessment

1.3.4 HTGR AIPA

1.3.5 LMFBR LOA Approach

1.3.6 HTGR Systems and Applications

1.3.7 HTGR Safety Features

1.4 Bases and Assumptions

1.4.1 Probabilistic-Risk Based

1.4.2 Promote Communication

1.4.3 Design Compatibility

1.4.4 Primary Objective

1.5 Safety Strategy

1.5.1 Lines of Protection (LOPS)

1.5.2 Attributes of the LOP Concept

1.5.3 Other Safety Plan Elements

1.6 Safety Goa $7 \mathrm{~s}$

1.6.1 Risk Acceptance Criteria

1.6.2 LOP Criterion

1.6.3 Meeting the Safety Criterion

1.6.4 Summary of Goals and Success Criterion

1.7 Structure of Plan

1.8 References

2 SAFETY PROGRAM INTEGRATION 27

2.1 Program Management 27

2.1.1 Program Plan Development 27

2.1.2 R\&D Prioritization 28

2.1 .3 Resource Allocation 28

2.1.4 Test Facility Requirements $\quad 28$

2.1.5 Liaison 29

2.2 Project Support 29

2.2.1 Design Criteria . 29

2.2.2 Reliability Integration 30

2.2.3 Licensing Support 30

2.3 Integrated Analys is 30

2.3.1 Risk Assessment 31

2.3.2 Critical Structures Integrity

2.3.3 Support Systems Reliability 33

2.3.4 External Events Accommodation - 34

2.4 References 35 


\section{TABLE OF CONTENTS (continued)}

Section

$\underline{\text { Page }}$

3 CORE ACCIDENT ACCOMMODATION

37

3.1 Reliable Operation (LOP 1)

37

3.1.1 Reliable Heat Removal

37

3.1.2 Reliable Plant Control

38

3.2 Prevent Core Heatup (LOP 2)

39

3.2.1 Reliable Shutdown Heat Removal 40

3.2.2 Reliable Reactor Shutdown 40

3.3 Limit Core Heatup (LOP 3) 41

3.3.1 Heat Removal Fault Accommodation 41

3.3.2 Reactor Shutdown Fault Accommodation $\quad 12$

3.4 Containment Mitigation (LOP 4) 43

3.4.1 Containment Atillosphere Response ${ }_{3 .} 43$

3.4.2 Radionuclide Removal 44

3.5 External Attenuation (LOP 5) 45

3.5.1 Natural Attenuation 40

3.5.2 Siting and Emergency Procedures - 46

$\begin{array}{lll}3.6 & \text { References } & 47\end{array}$

4 NONCORE ACTIVITY RELEASE ACCOMMODATION 49

4.1 Circulating Activity Accommodation $\quad 49$

4.2 Spend Fuel Accommodation 50

4.3 Radioactive Waste Accommudation 50

4.4 References $\quad 51$

APPENDIX A: COMPARISON OF HTGR-AIPA RESULTS WITH SAFETY PLAN A-1 LOP APPROACH AND SAFETY CRITERION 


\section{INTRODUCTION}

\subsection{PURPOSE}

The purpose of this document is to present a safety plan as part of an overall program plan for the design and development of the High Temperature Gas-Cooled Reactor (HTGR). This plan is intended to establish a logical framework for identifying the technology necessary to demonstrate that the requisite degree of public risk safety can be achieved economically.

This plan provides a coherent system safety approach together with goals and success criterion as part of a unifying strategy for licensing a lead reactor plant in the near term. It is intended to provide guidance to program participants involved in producing a technology base for the HTGR that is fully responsive to safety consideration in the design, evaluation, licensing, public acceptance, and economic optimization of reactor systems.

The safety program fulfills three basic functions to accomplish the quantitative safety goals:

1. Safety-related design tasks. The safety program defines and collects all the functional requirements for each LOP. It defines safety-related functional requirements for each system or structure which constitute an LOP. These functional requirements become part of the design criteria.

2. Safety-related research and development (R\&D) tasks. The safety program assesses current data against safety-related functional requirements to indicate where a safety-related R\&D effort is needed to assure that LOP goals can be met. The safety program defines an R\&D plan for each LOP.

3. Quantitative risk assessment. The safety program establishes the basis to quantitatively assess the plant safety risk. If the safety-related design and R\&D tasks are complete and successful, the quantitative risk assessment will not identify any accident sequences which exceed the risk limit line (i.e., the plant risk envelope will lie under the risk limit line); it will demonstrate that the preliminary safety goals have been achieved. If the risk assessment identifies any accident sequences outside the risk limit line, corrective action would be required case by case.

\subsection{SCOPE}

The public health and safety considerations uniquely assiciated with nuclear generated power can be categorized into two types: risks associated with operation of the nuclear plant itself, and risks accociated with nuclear fuel supply and disposal outside the plant. This plan deals only with considerations related to operation of the HTGR nuclear plant. 
Risks associated with the operation of the nuclear plant may be further categorized in terms of the location and magnitude of radioactivity within the plant. As long as adequate cooling is provided, the bulk of the radioactivity is located in the coated fuel particles of the HTGR graphite core. Other smaller radioactivity sites in the plant include the spent fuel; circulating activity in the coolant fluids; and waste gases, liquids, and solids. This plan deals with risks from all these radioactivity sites within the plant. However, because by far the largest radioactivity inventory is within the reactor core itself, the plan places its emphasis on risks associated with reactor core faults.

For large amounts of radioactivity to be released from the core fuel and present any potential hazard to the pubiic, the core must be severely - overheated. The yardstick used in this plan for measuring this hazard potential and other plant hazards is "risk," as measured by the probability of a given radioactivity release to the environment or some other measure of public consequence. Thu's, the study of the plant at all levels of operation is important to ensure that a requisite level of risk is not exceeded, either by reducing accident probabilities or consequences or both. The scope of this plan, therefore, includes activities which address the probability of accidents occurring which could lead to fuel overheating (hence the word "reliability" in the plan's title) as well as addresssing the plant's ability to mitigate the consequences of core fuel overheating should it occur. The latter scope implies that the plan encompasses activities directed at characterizing so-called "Beyond Design Basis" accidents.

While providing a structure within which the necessary safety-related $R \& D$ activities can be identified, this plan does not identify specifically implementing milestones, funding, priorities, and schedules. These will be the subject of subordinate implementation and work plans to be issued separately.

\subsection{BACKGROUND}

\subsubsection{Licensing Requirements}

In the application for a nuclear power plant construction license, the applicable federal regulations specified in Title 10 of the Code of Federal Regulations (10 CFR) require that a preliminary safety analysis report provide analysis and evaluation with the objective of assessing the risk to public health and safelty resulting from operation of the facility and to determine the margins of safety during all stages of plant operation as well as the adequacy of safety-related structures, systems and components. This assessment of risk has traditionally been made within the context of "multiple levels of safety design" on the basis of deterministic evaluations of conservative plant conditions ranging from anticipated operating modes all the way to accident conditions of low probability. The final judgment that no undue risk would result from plant operation is made by the Nuclear Regulatory Commission (NRC) on the basis of this spectrum of evaluations. 
As a means of quantitatively assessing the extent to which a particular reactor design meets the levels of safety assurance, it has become standard practice to define an enveloping set of events for which that design must. be shown to be capable of accommodating with little or no damage. This enveloping set of events is formally labeled the Design Basis. The NRC has required the license applicant to demonstrate that the plant can survive all events within the Design Basis without substantial core damage and in accordance with requirements set forth in applicable sections of the Code of Federal Regulations.

Beyond the events considered to be within the design basis is a residuum of events which can be postulated that lead to significant core damage and radioactivity release. Traditionally, such events have received little attention because they were perceived to have a vanishingly small probability of occurrence. However, with a rising population of operating nuclear plants increasing the likelihood of occurrence of such an event, with the greater awareness of the prevalence of common cause failures actually experienced in operating these plants, and following the accident at Three Mile Island, the NRC, as well as the nuclear industry as a whole, is paying increasing attention to beyond design basis events leading to a degraded core. The NRC is currently considering major changes to nuclear licensing and plant design for light-water reactors as part of its degraded core rule-making. The industry is responding via a major coordinated Industry Degraded Core Rulemaking (IDCOR) program. Whether light-water plants will have to be designed to accommodate a molten core is as yet undetermined. It is clear, however, that this will be an area of intensive research for which future applicants must provide a significant body of evidence to show that the public consequences of a damaged core are not catastrophic.

\subsubsection{HTGR Licensing History}

Despite the fact that there is only one small commerical HTGR operating in the U.S., namely the Fort St. Vrain (FSV) HTGR, the licensing review of the HTGR-Steam Cycle design has been significant. In addition to the FSV plant, the NRC has reviewed applications for commercial-sized units (References 1-1, 1-2) and a standardized safety analysis report (Reference 1-3). The application for Summit 1 \& 2 was docketed August 16, 1973, and the Safety Evaluation Report (SER) (Reference 1-4) issued by the NRC staff on January 31,1975 . When this application was dropped from an active status in late 1975, a Limited Work Authorization was close at hand. A later, more in-depth NRC review of the HTGR concept is found in the GASSAR-6 Interim Safety Evaluation Report (ISER) draft (Reference 1-5) dated June 28, 1977. A complete list of the 1 icensing issues raised during the course of these reviews may be found in Reference 1-6.

Despite the NRC reviews accomplished to date, the generation of a body of in-house review guidance documents comparable to that for LWRs was never accomplished. The interrupted commercialization pattern of the HTGRs coupled with a rapidly changing regulatory situation for LWRs has unfortunately created a situation in which a new NRC familiarization process may be required in any future HTGR application and in which 
previous precedents may not apply. Although steps have been taken to reestablish the NRC review process via an ambitious schedule of submittals of licensing topical reports (LTRs) on selected safety issues, they have met with limited success.

\subsubsection{Probabilistic Risk Assessment}

Over the past years, reactor safety analysts have succeeded in developing more detailed mechanistic models of the various accident-related phenomena in ever larger accident analysis computer codes. These analytical tools have been used to predict the various scenarios of interest with increasing amounts of detail. While these analysis tools have provided safety analysts with a better appreciation of the range of consequences which should be associated with accident scenarios, they have not been useful in addressing two important aspects of safety analysis. First, the mechanistic analyses provide little insight into the likelihood of occurrence of the low-probability system failures which initiate an accident sequence. Second, a range of consequences can be predicted for each accident of concern by available tools. This range is due to the remaining phenomena uncertainties and lack of sufficient details in the models of these phenomena. The probability distribution which should be associated with the range of predicted consequences cannot be obtained from the mechanistic analysis itself.

In order to address these important issues, probabilistic analysis methods have been introduced in reactor safety analysis. A variety of techniques such as event trees, fault trees, failure modes and effects analysis, common cause analysis, and sensitivity analysis are now employed to address the initiator and accident sequence probability and consequence distribution issues. The availibility of both consequence and probability information has meant that the more meaningful quantity, risk, could be estimated.

In the past few years, assessments of the risk to be associated with a wide variety of endeavors have been conducted. The Reactor Safety Study (Reference 1-7) conducted on light water reactors by the NRC established the usefulness of risk assessment for reactor safety analysis. The NRC and others have a number of risk assessments currently under way on various plants including Limmerick, Browns Ferry, Crystal River, Indian Point, Oconee, Oyster Creek, Sequoyah, Susquehanna, and Zion. Similar studies have al so been completed for LMFBR and HTGR concepts (References 1-8, 1-9).

These probabilistic risk assessments (PRAs) provide a quantitative assessment of accident risks and have placed these risks in perspective with other societal risks so that objective evidence for judging acceptability has been made available both to the public and regulatory agencies responsible for licensing. In recent action, the NRC has established a PRA steering committee to select a technical working group to draft a guidebook on prodedures to follow in doing risk assessment. The NRC is also pursuing a plan to develop numerical probability goals to 
be employed in the rule making process (Reference 1-10). An ACRS subcommittee has been formed and has made an interim recommendation of quantitative safety goals (Reference 1-11). Other industry groups are similarly actively studying and recommending the institution of numerical goals. It can, therefore, be expected that the application of PRA techniques will play an ever increasing role in the regulatory process of the future.

\subsubsection{HTGR AIPA}

In February 1974, General Atomic began, under ERDA (now DOE) sponsorship, a program of applying probabilistic risk assessment methods in the study of the safety of high-temperature gas-cooled reactors. The study is entitled "Accident Initiation and Progression Analysis" (AIPA). The initial primary objective of the AIPA study was to make recommendations for the HTGR safety research program. Following the initial work, the objective was redirected toward generating information to help develop future regulatory requirements uniquely appropriate for HTGRs.

Since its initiation the AIPA program has provided an impressive body of HTGR safety-related information and contributed in a number of areas to the advancement of PRA techniques. Early progress made in defining the important safety issues for HTGRs is documented in a seven volume status report (Reference 1-12). This initial report received a wide distribution from which critical comments were actively solicited and received from sources such as: NRC, Brookhaven National Laboratory, Los Alamos Scientific Laboratory, Oak Ridge National Laboratory, Aerojet Nuclear Company (now EG\&G), University of Tennessee, KFA (Federal Republic of Germany), and the Safety and Reliability Directorate of the United Kingdom Atomic Energy Authority.

In April of 1978 progress of the AIPA program was again reported in a comprehensive document, (Reference 1-9), including a more detailed consequence assessment of core heatup events.

\subsubsection{LMFBR LOA Approach}

Recently the DOE-funded LMFBR Safety Program has developed a Line of Assurance (LOA) approach as a management tool to aid in structuring, manaing, and communicating a comprehensive safety development program. A similar approach is proposed in this document for use in the HTGR program.

The LOA approach combines the basic elements of the multiple level of safety design approach and the quantitative risk-based approach into a methodology which facilitates the LMFBR safety planning. The LOA approach is based on the concept that multiple barriers are provided in the plant design to protect against accident progression. The four LOAs selected for the LMFBR are:

LOA-1: Prevent Accidents

LOA-2: $\quad$ Limit Core Damage

LOA-3: Maintain Containment Integrity

LOA-4: Attenuate Radiological Consequences 
A comprehensive LMFBR Safety Program Plan along the lines of assurance approach has been prepared and is currently in use by DOE

(Reference 1-13). This approach or a similar approach is also being considered for use by $\mathrm{DOE}$ in directing the expanding light-water reactor safety program.

\subsubsection{HTGR Systems and Applications}

The HTGR core is cooled with pressurized helium; moderated and reflected with graphite, and fueled with a mixture of uranium and thorium fuel particles with individual ceramic coatings. It is constructed of prismatic hexagonal graphite blocks with vertical holes for coolant channels, fuel rods, and control rods. The entire reactor core, together with other major primary system components, is contained in a multicavity, prestressed concrete reactor vessel (PCRV). In addition to the primary coolant loops, auxiliary cooling loops consisting of a helium/water heat exchanger and electric motor-driven circulator are provided. Should the main loops be unavailable, coolant gas is circulated from the reactor core through this auxiliary system via intermediate water loops for ultimate rejection from cooling towers to the atmosphere. The PCRV and ancillary systems are housed inside a reactor containment building which is a conventional steel-1ined reinforced concrete structure. Balance-of-plant systems and equipment are arranged and housed in separate buildings similar to light-water reactor plants. Figure 1-1 shows a cutaway of a typical HTGR nuclear steam supply system.

Several different HTGR applications are currently under investigation as follows:

Steam Cycle (SC) In the HTGR-Steam Cycle design, the reactor systems described above are employed to generate high-temperature, high-pressure steam for either electricity production or for the cogeneration of steam and electricity for industrial process applications. To achieve efficient energy conversion, steam is generated at the elevated conditions of $2500 \mathrm{psi} / 1,0050 \mathrm{~F}$, whereas the primary helium gas conditions are maintained in the low range of HTGR capability, approximately 1,3000F.

Sensible Energy Storage Within the temperature regimes of the HTGR-SC, utilization of a sensible energy storage system whereby reactor thermal energy is transferred to a high temperature heat transfer salt is under investigation. The salt is then stored at $1,000^{\circ} \mathrm{F}$ t. $1,100^{\circ} \mathrm{F}$ and later transported to the point of use.

The sensible heat from the plant can thus be utilized via a heat exchanger either for a direct heat process or to produce steam up to $950^{\circ} \mathrm{F}$. The cooled salt would then be returned to the central station.

Gas-Turbine (GT) The HTGR-Gas Turbine configuration consists of two power conversion loops each containing a helium gas turbine coupled to an electrical generator. The loop equipment includes recuperators and precoolers located around the central core cavity 
with a system of internal ducts connecting to the reactor core. The use of this direct Braytor thermodynamic cycle with its high-temperature waste heat allows the efficient application of dry cooling with a resulting efficiency of approximately $40 \%$. To achieve this efficiency requires that the reactor system operate to coolant temperatures up to $1,5600^{\circ}$.

Reformer (R) In the HTGR-Reformer application, a portion of the reactor thermal energy is converted to a storable/transportable energy form through the use of a highly endothermic reversible chemical reaction whereby methane and water are combined in the presence of a catalyst to form a synthesis gas of hydrogen and carbon monoxide. The balance of the reactor thermal energy is used for base load electricity generation through the conventional steam cycle. In a closed cycle application, the chemical energy is transported to remote locations utilizing pipelines and converted to thermal energy through an exothermic methanation reaction providing heat at temperatures in the range of 1,1000F. To achieve high conversion efficiencies the reactor system must operate with coolant temperatures up to $1,5600 \mathrm{~F}$.

\subsubsection{HTGR Safety Features}

The HTGR has a number of inherent characteristics that condition the risks of HTGR operation. These are summarized in Table 1-1 and are described as follows:

- Helium Gas as a Coolant - A fundamental property of a noncondensable gas is that it totally occupies the space it is in and, so confined, obeys a simple linear temperature-pressure relationship. Because there is no liquid-gas interface to be considered, unambiguous measurements of temperature and pressure indicate the state and location of the coolant. A loss of coolant cannot occur; depressurization only can occur, and this is accommodated without any concern for the consequences of a change in phase, which results in a degradation of fuel cooling capability. Adequate core cooling is possible even at atmospheric pressure. Helium conlant is al so chemically and neutronically inert; helium cannot react with core components and it does not contribute to or affect the nuclear chain reaction.

- Ceramic Core and Reflector - The core and reflector structure is composed of graphite, a material that sublimes at about $3800^{\circ} \mathrm{C}$ and retains good strength to above $2500^{\circ} \mathrm{C}$. The stucture weighs almost $3 \mathrm{milli}$ ion pounds; and the associated heat capacity, together with the high temperature capability and low power density, ensures that reactor temperature. transients will proceed very slowly. The slow thermal response provides a forgiving reactor since the behavior of the system is more readily predictable and more time is available to prevent transients from progressing into major accidents. Time 
is available for equipment repair, system adjustment, or other corrective action. For example, extended interruptions in core cooling system operation of the order of 30 minutes can be tolerated before damage to the core flow orifices and control rods would occur.

- Coated Particle Fuel - Another area of concern to both safety and plant maintenance relates to the possible migration of fission products. The coatings on the individua? HTGR fuel particles constitute tiny independent pressure vessels which contain the fission products. A total interruption of the core cooling systems would have to continue for about 3 hours before any fuel damage would occur and about 20 hours before $50 \%$ of the core radioactivity would be released. Time is thus provided for fisson product decay and for mitigating operator actions.

- Prestressed Concrete Reactor Vessel - The safety advantagcs of using a PCRV for containment of the entire primary system, a feature facilitated by the use of a noncondensable coolant., stem primarily from the redundancy of the load-bearing steel tendons. The independence and redundancy of these tendons provide a barrier to fault propagation within the vessel. The tendons are shielded from the effects of irradiation by the concrete. The steel liner functions as a nonload-bearing seal that is always held in compression by the surrounding prestressed concrete, a design feature which greatly limits the possibilities of fault propagation in the liner. The necessary liner cooling arrangements, moreover, furnish an additional available heat sink.

\subsection{BASES AND ASSUMPTIONS}

The plan presented in succeeding sections has a number of underlying assumptions and bases. Several of the more important of these are described below.

\subsubsection{Probabilistic-Risk Based}

The plan should be probabilistic-risk based, i.e., goals should be quantifiable in probabilistic terms and relatable to some overall targets with respect to minimizing the public risks of plant operation. Goals should be assigned consistent with present and perceived future goals for the LWR industry.

\subsubsection{Promote Communication}

The plan should be structured so as to promote and strengthen. communication on HTGR safety, i.e., the plan's top level strategy should be kept simple and understandable to as broad an audience as possible. Besides identifying weak points, the plan should be capable of "showcasing" advantageous safety attributes of the HTGR as we 11 . To the 
extent practical, the plan should parallel safety plans for other DOE programs (particularly LWR and LMFBR) to maximize the ability to transfer information between such programs.

\subsubsection{Design Compatibility}

The plan should not conflict with known licensing requirements or current design features of the HTGR. The plan should be broad enough to. encompass all the alternative HTGR applications currently under investigation, yet provide a basis for comparison.

\subsubsection{Primary Objective}

The primary objective of the plan is to aid in the identification and prioritization of safety-related research and development requirements for the HTGR. However, the top leve 1 safety strategy and goals identified towards this objective are, of necessity, sufficiently broad to encompass and influence design, maintenance, and operation activities where safety related.

\subsection{SAFETY STRATEGY}

The HTGR safety program will employ a strategy which divides the technology development into three program elements. The first element includes five lines of protection (LOPs) against core-related accidents, the second element supports noncore related safety considerations, and the third element supports safety R\&D integration of other elements and between other programs. Listed by element, these are:

1. Core Accident Accommodation (LOP 1 through 5)

2. Noncore Activity Release Accommodation

3. Safety Program Integration

Element 1 and the concept of lines of protection is discussed in detail below. Elements 2 and 3 are described further in later sections of this document.

\subsubsection{Lines of Protection (LOPs)}

The line of protection (LOP) approach to HTGR safety is based on the concept that multiple and independent barriers or restraints exist in an HTGR plant which function to prevent the progression of accident sequences which could result in harm to the public. The five LOPs, their functions, and the associated physical systems and barriers are described below and illustrated in Figure 1-2.

\subsubsection{Reliable Opcration}

It is the function of LOP-1 to prevent the initiation of events which could lead to a core power/heat removal imbalance significant enough to require safety systems actuation. LOP-1 employs the 
operational, maintenance, design, and inherent features provided in the HTGR for purposes of normal eletrical power generation and/or process heat generation to accomplish this function. This includes the following systems: reactor core, reactor vessel and internals, plant control system, main loop cooling system, and associated balance of plant systems. LOP-T deals primarily with activities addressed at ensuring the reliability of these systems.

\subsubsection{Prevent Core Heatup}

It is the function of LOP-2 to provide automatic shutdown and cooldown of the core in the event that the normally operating systems in LOP-1 fail. LOP-2 includes those sytems dedicated to providing this - safety function and which are largely independent of the systems necessary for normal electrical power generation. This includes the following systems: core auxiliary cooling system, reactor trip and plant protection system, and supporting balance of plant systems. LOP-2 deals primarily with activities addressed at ensuring the reliability of these systems.

\subsubsection{Limit Core Heatup}

The function of LOP-3 is to demonstrate that the inherent response of the reactor system will limit or restrict the core heatup, limit the radionuclide release, and prevent a threat to radionuclide containment even in the event of LOP-1 and 2 failure. The inherently slow heatup response of the HTGR core allows this function to be provided free from immediate human intervention or external energy sources, providing additional protection against common cause failure mechanisms. LOP-3 makes use of the following HTGR features: core heat capacity and low power density, high temperature stability of the ceramic fuel and graphite structural material, reserve shutdown system and the cooled PCRV liner. LOP-3 deals primarily with assessing the margins inherent in the reactor system delaying core heatup and assessing actions which can be taken to "turn around" the core heatup during the time interval provided.

\subsubsection{Containment Mitigation}

The function of LOP-4 is to demonstrate that containment system integrity is maintained to delay and limit the release of radionuclides to the environment even in the event of an unrestricted core heatup resulting from failure of LOPS 1 through 3. LOP-4 includes the following systems: containment building and containment isolation and cleanup systems. LOP-4 deals primarily with considerations of pressure buildup, flammable gas control, heat load accommodation, and plateout and cleanup actions within the containment.

\subsubsection{External Attenuation}

The function of LOP-5 is to demonstrate that naturally occurring and engineered external attenuation mechanisms serve to limit the quantity of radioactivity which can be transported into and through the environment 
and to the public even in the event of failure of the preceeding four LOPs. LOP-5 makes use of the following features: delays in radionuclide release from the core, settling and plateout of radionuclides and site features. LOP-5 deals primarily with establishing HTGR siting characteristics and emergency procedure planning.

\subsubsection{Attributes of the LOP Concept}

The LOPS defined above and as illustrated separate the core heatup sequence into its major components. Each successive LOP is only seriously challenged if the preceding LOP has failed. Hence the failure of each preceeding LOP defines the initial conditions for examining the response of each succeeding LOP. Each LOP serves to independently reduce - the probability and consequence, hence risk, of the core heatup accident sequence.

The portioning of the accident sequence in such a fashion allows the safety program manager to single out and place emphasis on the key aspects of the core heatup sequence which require safety R\&D attention. The manager can further control the emphasis placed on each of the accident sequence elements by the selection of probability and consequence goals for each. This portioning further allows the assignment of more realistic probability goals. Arguments can be centered not around rare events, but rather the understanding of systems and phenomena having failure probabilities in the more demonstrable range of $10^{-1}$ to $10^{-3}$.

It should be recognized in the above that LOPS 1 and 2 deal with engineering features provided in the normal course of addressing those safety issues which must be considered within the traditional Design Basis of the HTGR. LOPs 3 through 5 address the capability of the HTGR to accommodate and mitigate events traditionally considered beyond design basis. This approach, therefore, extends the traditional

defense-in-depth concept to consider the accommodation of accidents more severe than design basis. It should be also noted that the last line of protection, "Natural Attenuation," deals with factors largely generic to all reactor concepts and, as such, is largely design-independent except as to how HTGR accident sequence timing may enhance the benefit of such factors. It is this latter aspect which is considered to be of importance to the HTGR safety program.

\subsubsection{Other Safety Plan Elements}

The fundamental simplification of the HTGR safety characteristics afforded by the line of protection approach should facilitate rational and cost-effective decision making for HTGR design and R\&D planning. It should be recognized, however, that this simplificiation is not gained without some loss of information. For example, the LOP approach necessarily emphasizes HTGR safety with respect to core heatup accidents. It is, therefore, important to ensure that such accidents are indeed the risk dominant ones so that research efforts are not misdirected. Further, the LOP approach assumes an element of independence between each LOP. It is, therefore, of critical importance to ensure that there are not events which "short circuit" one or more of the LOPs preventing the cumulative probability targets from being met. 
Additionally, any interfacing information between LOPs must be carefully defined and continually updated to allow research efforts to proceed as independently as possible. It is for these reasons that the safety plan includes two elements in addition to the element providing lines of protection for core accidents, namely the noncore activity release accommodation and the safety program integration elements: the former element addressing risks associated with accidents not involving the reactor core; the latter addressing concerns relevant to ensuring a consistent, independent, and realistic division of LOP activities.

\subsection{SAFETY GOALS}

There are two separate aspects to the problem of implementing a - quantitative risk-based approach to identifying technology requirements for each of the lines of protection identified previously. First, it is necessary to establish the overall risk acceptance criteria (i.e., risk envelope) for the plant. Second, goals must be allocated to each of the LOP's consistent with this overall acceptance criteria.

\subsubsection{Risk Acceptance Criteria}

The first aspect, that of establishing overall risk acceptance criteria, is beyond the scope of this document. The reader is referred to Reference 1-14 for a summary of the national and international policy actions being taken with respect to establishing numerical safety goals. To date, risk acceptance criteria have not been established for nuclear plants in the U.S. However, the NRC as well as a number of other industry groups are actively considering establishing such criteria.

Historically, in order to ensure that the risk to the public from nuclear power is small compared to other risks of life, the NRC has stated as a safety objective that the likelihood of a nuclear plant accident having serious public consequences should have an average recurrence interval of at least a thousand years for all nuclear plants combined (Reference 1-15). For an anticipated population of about one thousand nuclear plants in the U.S. this implies an objective of $10^{-6}$ per year for an individual plant. Serious consequence was defined as potential consequences in excess of 10CFR100 guidelines (i.e., consequences potentially acutely affecting the limiting offsite individuals' health). Further, considering very conservative information on the consequences of an LWR core meltdown, it was assumed that a core meltdown event was synonymous with exceeding 10CFR100 Timits. Therefore, the design must assure the prevention of a core meltdown to a probability of $10^{-6}$ per reactor year.

More recent evidence, particularly the Reactor Safety Study (WASH-1400) and the accident at Three Mile Island, has suggested that current generation 1 ight-water reactors may fall well short of a target of $10^{-6}$ per year for preventing system failures leading to a core meltdown. However, this recent evidence also suggests that the consequences of an LWR core meltdown, when realistically evaluated, are substantially more benign than orginally perceived. Thus, it is only 
with some improbability that a core meltdown would result in acute public health consequences. For this reason, recent industry dialogue on the subject has centered about ensuring a core meltdown frequency in an LWR is less than $10^{-4}$ to $10^{-5}$ per year and that large scale consequences to the public do not result from such accidents with a probability of $10^{-1}$ to $10^{-2}$, thus ensuring the likelihood of acute public health effects to be less than approximately $10^{-6}$ per reactor year.

With respect to advanced reactor concepts such as the HTGR, the most recent NRC statement on numerical goals has been during the review of the CRBR - liquid metal breeder reactor application. During the course of this application, the NRC declared an objective (Reference 1-16) that there be no greater than one chance in one million per year for potential consequences greater than 10CFR100 guidelines for an individual plant. It should be noted that this objective was stated well after the final issue of the WASH-1400 LWR study.

Although there is not yet a consensus on a numerical goal within the industry or NRC, there is an element of commonality between the historical NRC goal of $10^{-6}$ per reactor year for not exceeding 10CFR100 and current dialogue suggesting a goal of $10^{-6}$ per reactor year for not causing acute health effects or death in an individual member of the public. What is emerging as different are the proposed design measures and degree of conservatisms to be taken to meet this goal. Therefore, $x$ while the debate continues, it is proposed that the following top level core accident safety criterion be instituted for the HTGR safety program:

A top level objective of the HTGR safety program is to ensure that there be no greater than one chance in one million per plant year of an accident causing acute life-threatening health effects in any individual member of the public based upon a realistic assessment of accident consequences.

The objective above provides a single point on a probability versus consequence plot to establish a risk envelope. Other regulatory actions may be considered to establish other points on this curve. For example, again, in the case of the CRBR - liquid metal breeder reactor application, the NRC has declared that the design should assure the capability to minimize the risks assuciated with core meltdown events to an extent comparable to LWR designs. If the associated LWR risks can be quantified, as was done by the Reactor Safety Study group, and agreed to, this provides a risk curve at the lower end of the probability. spectrum. Additional points at higher probabilities can be established by maintaining the objective of not exceeding the consequences required in the code of Federal Regulations to be met by LWRs, for example, 10CFR50, Appendix I limils lo be met during normal plant operation. It should be cautioned that in the latter case, economic considerations (i.e., the concept of as low as reasonably achievable) play a major role in establishing limits--divorcing the limits from being based purely on public health considerations. 
Joksimovic and 0'Donnell of General Atomic Company (Reference 1-17) proposed the industry adoption of an individual risk limit line which is generally consistent with what has been discussed above. This limit line, for our purposes, is uniquely identified by two risk points. The first corresponds to the 10CFR50 Appendix I limit at a frequency of one per reactor year. The second corresponds to the limiting dose level at which no acute fatalities would be expected in the limiting members of the public (i.e., those located on the site boundary) at a frequency leve 1 of 10-6. Figure 1-3 displays the proposed limit line in terms of multiples of the IOCFRIO0 limits. Until such time as the NRC adopts formal numerical safety goals, it is proposed that the risk limit line of Figure 1-3 be used for purposes of guiding the HTGR safety program.

\subsubsection{LOP Criterion}

The problem of allocating criterion to each HTGR line of protection does not have a unique solution. Even with a well defined overall risk criterion, there are many combinations of weightings which might be assigned to each LOP consistent with the criterion. This aspect of the allocation process at once requires (and affords the opportunity to) the safety program manager to establish at a very fundamental level the areas of relative design and research emphasis desired. The optimal allocation of LOP criterion is ideally attained by minimizing plant operating, design, and research costs. In practice, however, the manager may be constrained by limited information or by past precedents. In quantifying criterion under such circumstances there is always a danger of selecting criterion which are nonoptimal. However, the alternative of not providing success criteria to focus the research and development program may be considerably more wasteful of program resources.

The early identification and numerical quantification of LOP criterion is, therefore, considered to be essential. As new information is learned, reallocations of the overall safety goals to each LOP may be in order; the LOP structure should be most useful in conducting trade-off studies to determine the optimal goal allocation. In the following, criterion are proposed for each LOP to initiate dialogue on the subject between program managers.

It first may be considered as how to best allocate the 10-6 per year target identified in the previous section. In principle, in order to keep the target for each LOP as small as possible, the target could be divided up entirely among the five LOPs. This however, would leave no barrier for ensuring that potential residual risk criterion below the 10-6 per year level are satisfied. Therefore, we chose to divide the 10-6 target among the first four LOPs, leaving it to LOP-5 to cnsurc the acceptability of residual risks resulting from accident sequences below $10^{-6}$ per reactor year.

Historically, the primary emphasis in design has been to ensure the provision of reliable engineered safety systems (namely LUP-2) to prevent accident initiators from leading to radioactivity release from the core. This has been no different. for the HTGR. Placing emphasis on the prevention of core heatup is also desirable from a plant investment point 
of view. The result is that in an existing design, these safety systems play the dominant role in accident risk reduction. It is generally accepted that demand failure probabilities for such systems in the range of $10^{-3}$ to $10^{-4}$ are achievable. (By way of comparison, the availability of a typical automobile engine is in the range of $10^{-3}$ to $10^{-4}$ per demand.) Lower failure probabilities may be achievable, but this requires the demonstration of improved understanding of the means to eliminate common cause failures. Considering that several such systems must perform to accomplish the LOP-2 function, a goal of $10^{-3}$ appears to be realistically achievable.

Having set the LOP-2 criterion at 10-3 leaves a portioning of $10^{-3}$ to the remaining three, LOPs 1, 3, and 4. For simplicity, we may allocate this remainder equally, resulting in a criterion of 10-1 for. each. The assignment of less stringent probability targets to LOPs 3 and 4 is particularly desirable where the complexity of core heatup phenomena must be quantified.

The completed allocation is illustrated in Figure 1-4 and summarized in Table 1-2. Some discretizing of the consequence criterion for the LOPs has also been identified in the figure for purposes of. simplification, to recognize that there are limits to our ability to predict system failure probabilities, and to ensure some margin in the consequences of a core heatup event. It should be emphasized that at the higher frequency events dealt with by LOPS 1 and 2, economic criteria are. expected to be more limiting than the identified safety criteria. Safety program emphasis, therefore, in LOPs 1 and 2 will be assuring that the reliability criteria are met. At the lower frequency levels of LOPs 3 through 5, public consequence criteria become limiting and, therefore, the safety program must emphasise the attainment of both reliability and consequence goals.

\subsubsection{Meeting the Safety Criterion}

Establishing the methods for demonstrating that the HTGR is successful in meeting the numerical criterion described previously is beyond the scope of this document. Rather, it is the purpose of this document to establish the framework and success criterion within which such methods are to be employed. Clearly, the development and documentation of such methods is an important follow-on activity to this one.

In general, the methods employed should aim at assessing the system and function failure probabilities and consequences in a realistic manner. Methodology established by the HTGR-AIPA program is available to accomplish this. Further, a system for ranking safety program requirements on the basis of the degree to which the numerical targets appear to have been achieved is necessary. For example, if the mean frequency or consequence of an event lies outside the desired target, design improvements may be required. If, however, the mean is within the target, but the uncertainty distribution lies substantially outside the target, the event may be a candidate for further safety research to reduce uncertainties. 


\subsubsection{Summary of Goals and Success Criterion}

The overall goals and proposed corresponding success criterion may now be summarized.

\subsubsection{Overal1 Risk Limits}

The HTGR safety program shall develop an integrated technology base to demonstrate that HTGRs can be designed, constructed, and operated to present limited risks to the public health and safety. The risk limit line of Figure $1-3$ is proposed as an interim success criterion.

\subsubsection{Core Accident Risks}

The HTGR safely program shall devclop a technology hase to support five lines of protertion for the public which limit the risks of HTGR core heatup accidents. LOPS 1 through 4 shall demonstrate that the HTGR design presents no greater than one chance in urle million per plant ycar of an HTGR core heatup accident causing offsite doses in excess of those identified in 1OCFRI00. LOP 5 shall assure that the HTGR is sited and emergency procedures established in such a manner that the residual risks associated with failure of LOPs 1 through 4 do not exceed those determined as causing acute 1 ife-threatening health effects in any member of the public.

LOP 1. Activities shall demonstrate that the systems provided in the HTGR to provide normal electrical power and/or process heat generation prevent, with high reliability, the initiation of events requiring safety systems actuation. The failure frequency criterion for this function shall be less than once in ten years.

LOP 2. Activities shall demonstrate that the dedicated safety systems provided in the HTGR prevent the occurrence of a core heatup, given a failure of LOP 1 systenis, w1 th very high reliability.. The failure frequency criterion for this function shall be less than one-in-one-thousand per demand.

LOP 3. Activities shall demonstrate that the response of the reactor system will inherently restrict core heatup and prevent a consequential threat to radionuclide containment even in the event of LOP 1 and 2 failure. The failure frequency criterion for this function shall be less than one-in-ten per demand.

I.nP 4. Activities shall demonstrate that containment system integrity is maintained to delay and limil the release of radionuclides even in the event of an unrestricted core heatup resulting from failures of the first three LOPs. The failure frequency criterion for this function shall be less than one-in-ten per demand.

LOP 5. Activities shall demonstrate that naturally occurring external attenuation mechanisms coupled with siting and emergency procedures precautions limit the quantity of radionuclides which can 
be transported from the core fuel to the public even in the event of LOP 1 to 4 failure. The criterion for this function shall be to ensure that the residual risks from failure of the first four LOPs do not exceed those considered acceptable for LWRs.

\subsection{STRUCTURE OF PLAN}

To assist in the achievement of the safety-reliability goals defined in the previous sections, the HTGR Safety-Reliability Program Plan has à work breakdown structure. The purpose of this structure is to identify in a complete, hierarchical fashion all the products necessary to accomplish program objectives. Figure 1-5 shows the top two levels of the work breakdown structure. Each element of the structure is marked with the corresponding section of this plan which identifies element. objectives and lower levels of the structure where, eventually, work packages are identified.

The top level of the work breakdown structure may be seen to be complete in the sense that it identifies products pertaining to all radioactivity sites in the plant. The "Core Accident Accomodation" element is subdivided along the lines of protection discussed previously. The "Noncore Activity Release Accommodation" is subdivided in accordance with the radioactivity sites in the plant lother than the reactor core). A "Safety Program Integration" element is also provided to ensure appropriate management functions, provide support to specific HTGR projects, and to perform integrated analyses as necessary to ensure the overall program objectives are met.

Each of the two levels shown in Figure 1-5 identifies a function which must be accomplished to achieve program goals. In general, the next levels of the work breakdown structure identify functions, systems which accomplish the function, and work packages in that order. Figure 1-6 illustrates this general hierarchical approach.

\subsection{REFERENCES}

1-1 "Preliminary Safety Analysis Report," Summit Power Station, Delmarva Power and Light Company.

1-2 "Preliminary Safety Analysis Report," Fulton Generating Station, Philadelphia Electric Company.

1-3 "General Atomic Standard Safety Analysis Report," GASSAR-6, Docket Number STN 50-535.

1-4 "Safety Evaluation Report by the Division of Reactor Licensing," U.S. NRC in the Matter of Delmarva Power and Light Company Summit Power Station, Units 1 and 2, Docket Numbers 50-450 and 50-451. 
1-5 "Partial and Preliminary Oraft Interim Safety Evaluation Report Related to the Review of the GASSAR-6 Nuclear Steam Supply System," General Atomic Company, U.S. Nuclear Regulatory Commission, Office of Nuclear Reactor Regulation, Docket Number STN 50-535, June 28, 1977.

1-6 "Selection, Strategy Analysis, and Options for Resolution of Key HTGR-SC Licensing Issues," Target Technology Ltd., March 21, 1978.

1-7 "The Reactor Safety Study," WASH-1400 (NUREG-75/014), October 1975.

1-8 "CRBRP Risk Assessment Report," C1inch River Breeder Reactor Plant Report CRBRP-1, March 1977.

1-9 "HTGR. Accident. Inttlalion and Progression Analysis Status Report," (Phase II Risk Assessment), GA-A15000, April 1978.

1-10 "P1an for Devcloping a Safety Goal," NUREg-0735, October 1980.

1-11 "An Approach to Quantitative Safety Goals for Nuclear Power Plants," NUREG-0739, October 1980.

1-12 "HTGR Accident Initiation and Progression Analysis Status Report," ERDA Report GA-A13617, General Atomic Company, October 1975 to January 1975.

1-13 "LMFBR Safety Program P1an," Division of Reactor Research and Technolngy, U.S. DOE, December 1979.

1-14 "A Summary of Safety Goals," Pickard, Lowe and Garrick, Inc.. (to bé 1ssued).

1-15 "Technical Report on Anticipated Transients Without Scram for Water-Cooled Power Reactors," Regulatory Staff, USAEC, WASH-1270, September 1973.

1-16 Letter from R. P. Denise, NKC, to L. W. Caffey, Director; C.RBR Project Officc, dated May 6, 1976.

1-17 Joksimovic, V. and L. F. 0'Donne11, "Quantitative Safety Goals for the Regulatory Process," General Atomic Company, October 1, 1980. 
TABLE 1-1. KEY INHERENT AND PASSIVE SAFETY CHARACTERISTICS OF THE HTGR

\begin{tabular}{|c|c|c|}
\hline $\begin{array}{c}\text { Inherent or } \\
\text { Passive Feature }\end{array}$ & Relevant Properties & Safety Significance \\
\hline Reactor core & $\begin{array}{l}\text { High heat capacity } \\
\text { Low poiver density } \\
\text { Strong negative temperature } \\
\text { coefficient } \\
\text { Graphite cannot melt but may } \\
\text { locally sublime } \\
\text { Coated particle ceramic fuel }\end{array}$ & $\begin{array}{l}\text { Slow transient response } \\
\text { Allows adequate time for remedial measures, } \\
\text { both within and external to plant } \\
\text { Fast-acting shutdown system not required } \\
\text { Structural integrity of core maintained for } \\
\text { days following loss of cooling } \\
\text { Slow controlled release of volatile nuclides } \\
\text { under no-cooling conditions }\end{array}$ \\
\hline Helium coolant & $\begin{array}{l}\text { Single-phase gas } \\
\text { Neutronically transparent } \\
\text { Chemically inert } \\
\text { Low stored energy }\end{array}$ & $\begin{array}{l}\text { No boiling, bubbles, liquid level, or pump } \\
\text { cavitation problem; no added coolant inven- } \\
\text { tory needed for core cooling, only forced } \\
\text { circulation } \\
\text { Negligible reactivity effects } \\
\text { No chemical fuel cladding-coolant interactions } \\
\text { Reduced containment damage potential }\end{array}$ \\
\hline PCRV & $\begin{array}{l}\text { Multiplicity of tendons } \\
\text { Tendons shielded by concrete } \\
\text { Concrete under compression. } \\
\text { Massive structure }\end{array}$ & $\begin{array}{l}\text { Failure of individual structural members } \\
\text { inconsequential } \\
\text { Neutron embrittlement and subsequent fracture } \\
\text { eliminated } \\
\text { Cracks self-sealing, do not propagate } \\
\text { Effective retention of radioactivity; retains } \\
\text { great fraction of heat escaping core }\end{array}$ \\
\hline
\end{tabular}


TABLE 1-2. HTGR LINES OF PROTECTION (LOPs) AND ASSOCIATED SUCCESS CRITERIA

\begin{tabular}{|c|c|c|c|c|c|}
\hline \multicolumn{4}{|c|}{ LOP Description } & \multicolumn{2}{|c|}{ Suczess Criteria } \\
\hline No. & Function & Systems/Features & $\begin{array}{l}\text { Chief } \\
\text { Radionuclide } \\
\text { Barrier }\end{array}$ & $\begin{array}{l}\text { Failure } \\
\text { Frobadility }\end{array}$ & $\begin{array}{l}\text { Cumulative } \\
\text { Failure } \\
\text { Probability }\end{array}$ \\
\hline 1 & $\begin{array}{l}\text { Reliable } \\
\text { Operation }\end{array}$ & $\begin{array}{l}\text { Normally Operating } \\
\text { Systems (MLCS, PCS, } \\
\text { Related BOP) }\end{array}$ & $\begin{array}{l}\text { Fuel Partizle } \\
\text { Coatings }\end{array}$ & $<10-1: y r$ & $<10-1 / y r$ \\
\hline 2. & $\begin{array}{l}\text { Prevent } \\
\text { Core Heitup }\end{array}$ & $\begin{array}{l}\text { Dedicated Safety Systems } \\
\text { (CACS, PPS, Related BOP) }\end{array}$ & $\begin{array}{l}\text { Fuel Particle } \\
\text { Coatings }\end{array}$ & $<10-3 / 0$ & $<10-4 / y r$ \\
\hline 3. & $\begin{array}{l}\text { Limit Core } \\
\text { Heatup }\end{array}$ & $\begin{array}{l}\text { Inheren: System Response } \\
\text { (core heat capacity, RSS } \\
\text { liner cooling) }\end{array}$ & Core \& PCPV & $<10^{-1 / 0}$ & $<10^{-5} / y r$ \\
\hline 4. & $\begin{array}{l}\text { Contairment } \\
\text { Mitigation }\end{array}$ & $\begin{array}{l}\text { Containnent Systems } \\
\text { (containment tldg, air } \\
\text { cleaning, isolation) }\end{array}$ & $\begin{array}{l}\text { Containme it } \\
\text { Building }\end{array}$ & $<10^{-1} / 0$ & $<10-6 / y r$ \\
\hline 5. & $\begin{array}{l}\text { External } \\
\text { Attenuation }\end{array}$ & $\begin{array}{l}\text { Natural and Engineered } \\
\text { Factors (decaw, settling, } \\
\text { plateout, siting, } \\
\text { emergency plaiss) }\end{array}$ & Distance \& Time & - & - \\
\hline
\end{tabular}




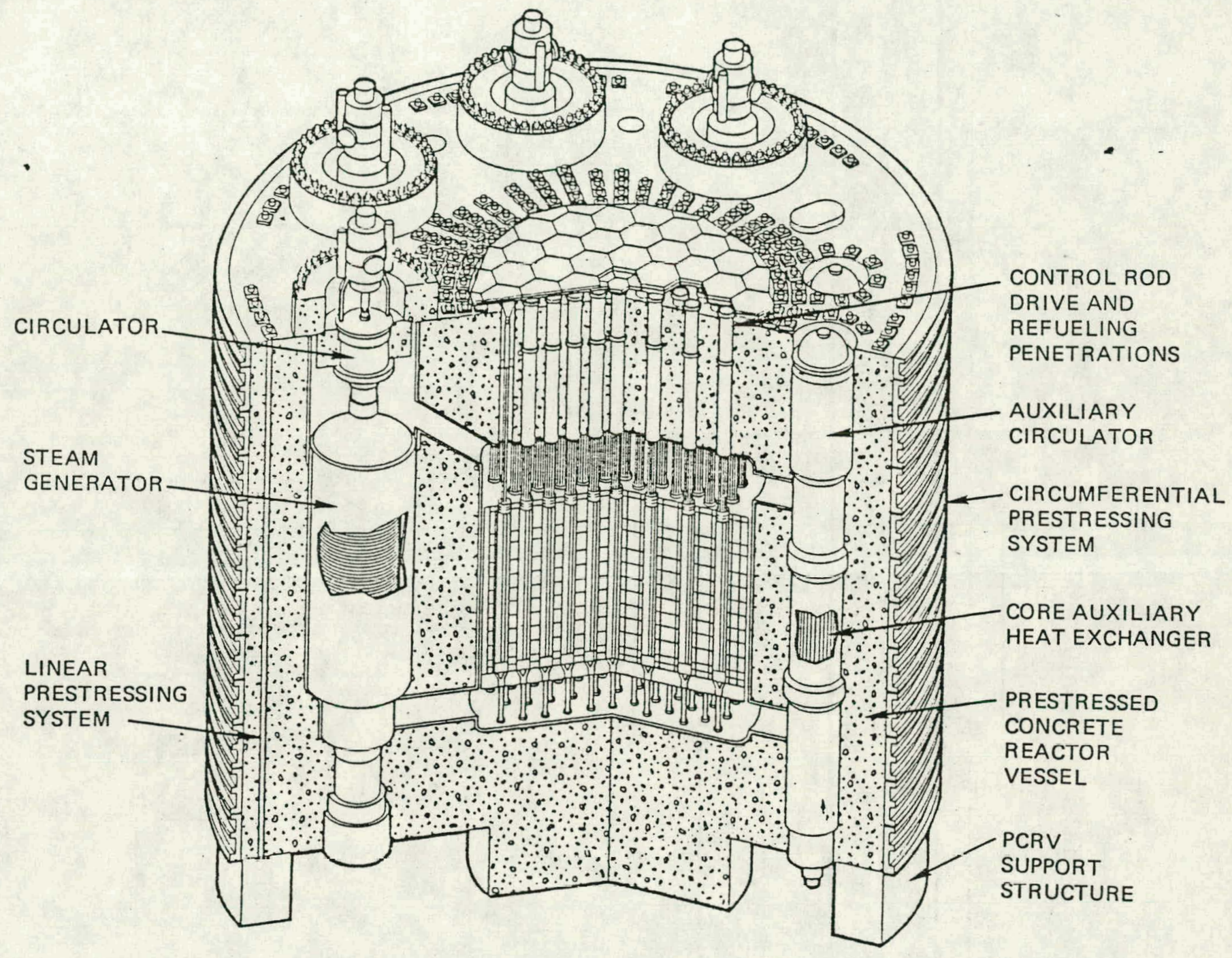

FIGURE 1-1. HTGR NSSS CUT-AWAY DRAWING (SC SHOWN) 


\begin{tabular}{|c|c|c|c|c|}
\hline \multirow[b]{2}{*}{$P_{1}, C_{1}$} & \multicolumn{2}{|r|}{ LOP FUNCTIONS } & \multirow{2}{*}{\multicolumn{2}{|c|}{$P_{4}, C_{4}$}} \\
\hline & \multicolumn{2}{|c|}{$P_{2}, C_{2}$} & & \\
\hline $\begin{array}{l}1 \\
1 \\
\text { RELIABLE } \\
\text { OPERATION }\end{array}$ & \begin{tabular}{l}
\multicolumn{1}{c}{2} \\
PREVENT \\
CORE HEATUP
\end{tabular} & $\begin{array}{l}{ }^{3} \\
\text { LIMIT }^{\text {CORE HEATUP }}\end{array}$ & \begin{tabular}{l}
\multicolumn{1}{c}{4} \\
CONTAINMENT \\
MITIGATION
\end{tabular} & \begin{tabular}{l}
\multicolumn{1}{c}{5} \\
EXTERNAL \\
ATTENUATION
\end{tabular} \\
\hline
\end{tabular}

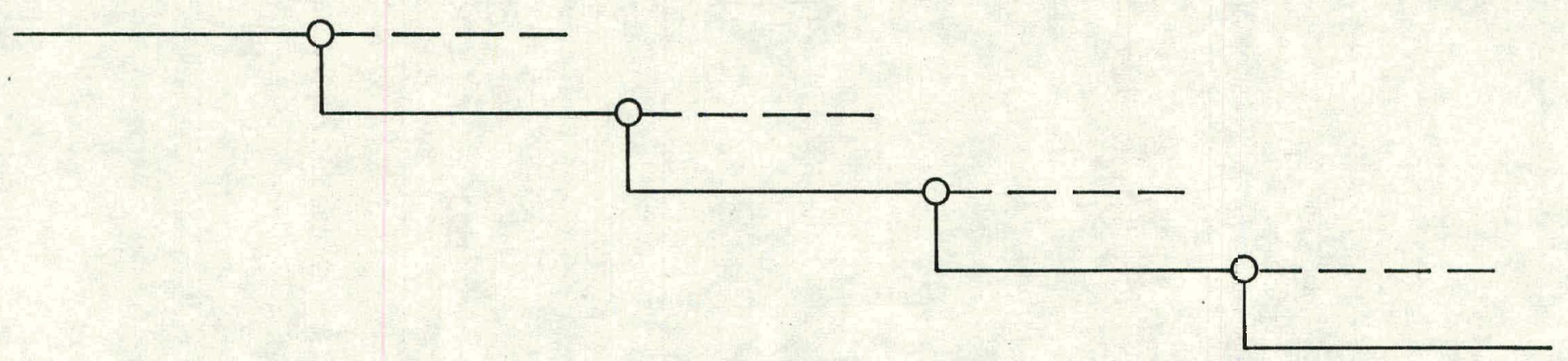

CORE HEATUP ACCIDENT SEQUENCE PHYSICAL BARRIEFS
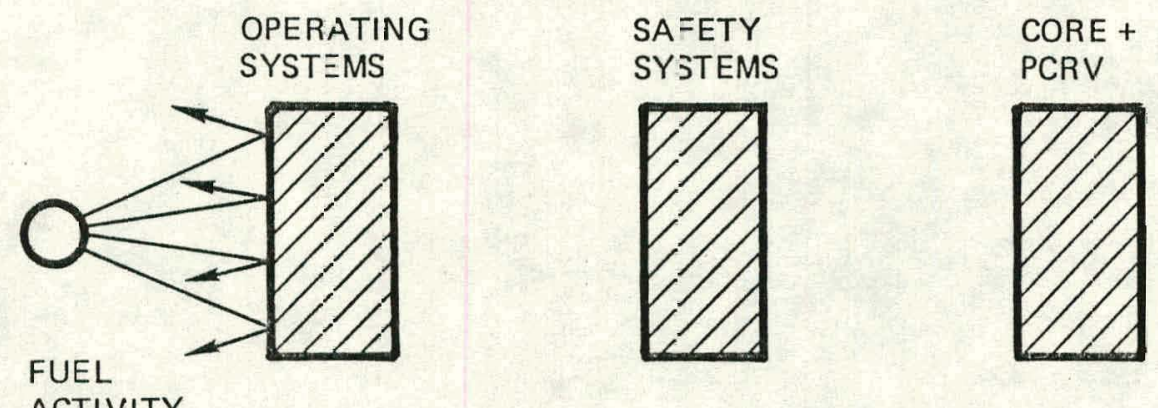

CONTAIN- TIME, DISTANCE MENT AND NATURAL FACTORS ACTIVITY

FIGURE 1-2. ILLUSTRATION OF LOP CONCEPT

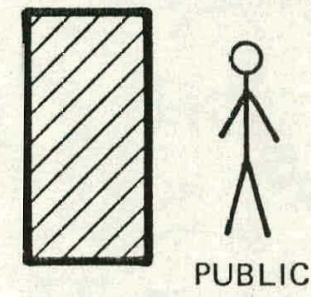




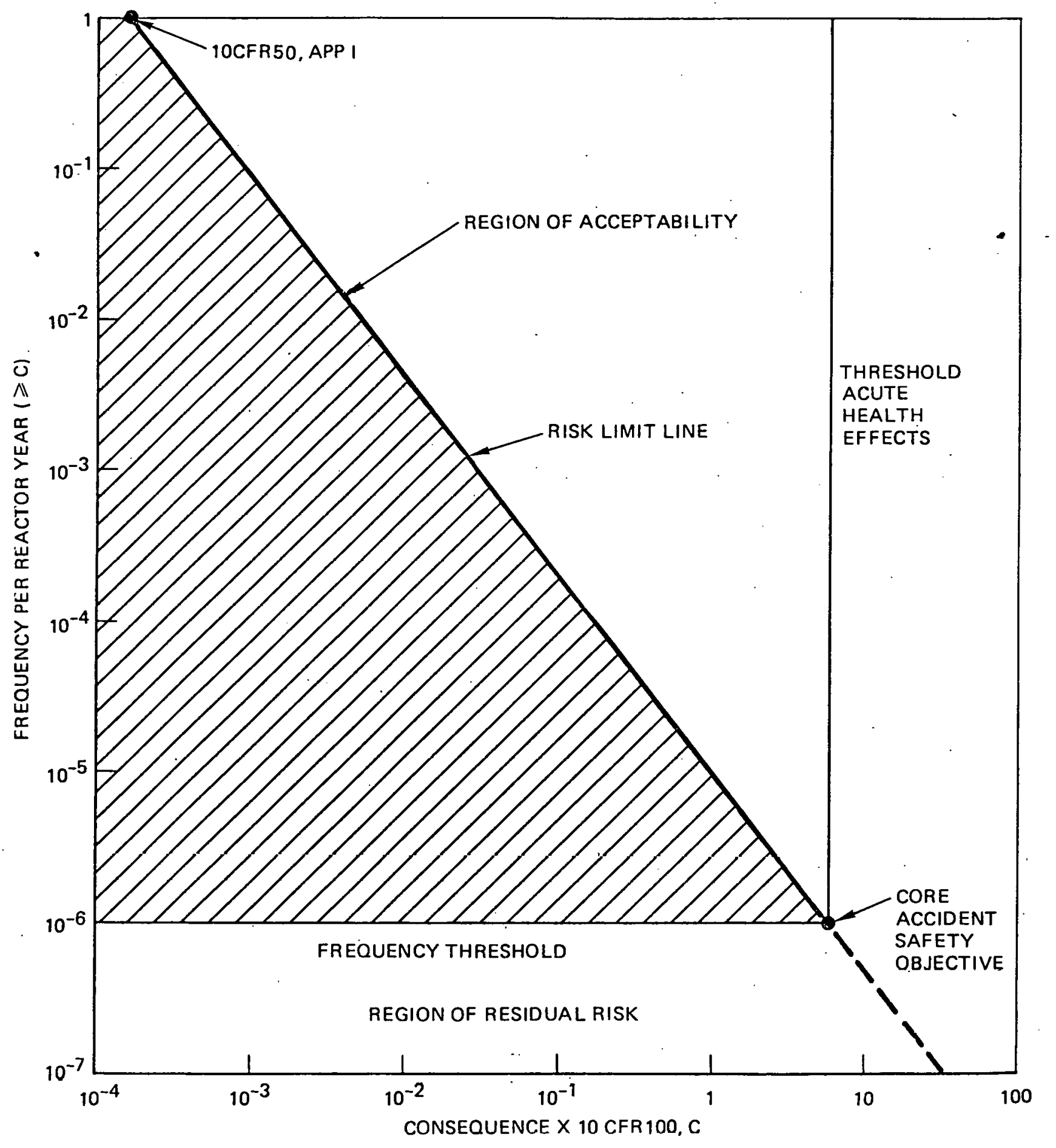

FIGURE 1-3. PROPOSED HTGR RISK CRITERION 


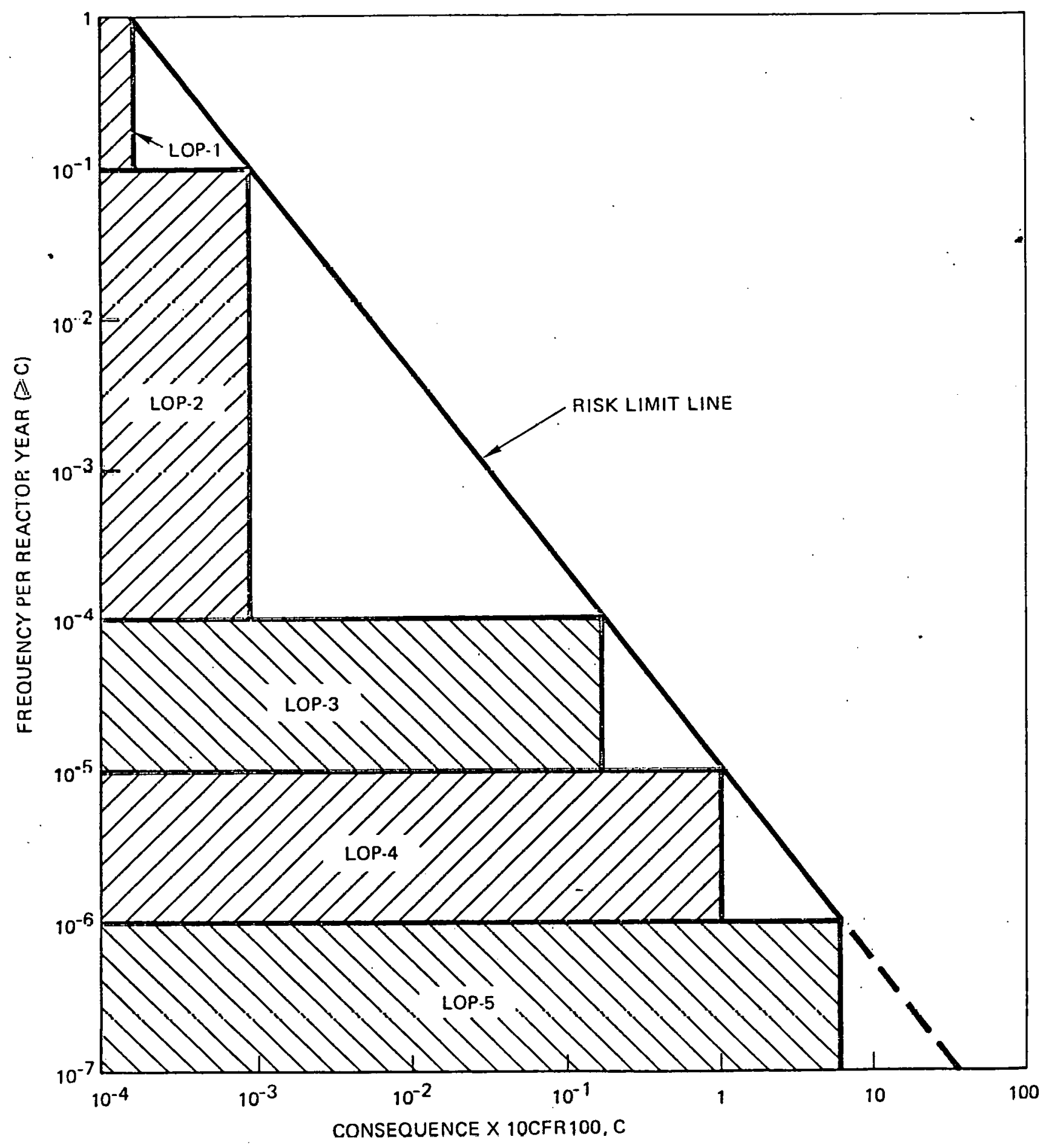

FIGURE 1-4. LOP GOAL ALLOCATION 


\section{HTGR SAFETY-RELIABILITY PROGRAM}

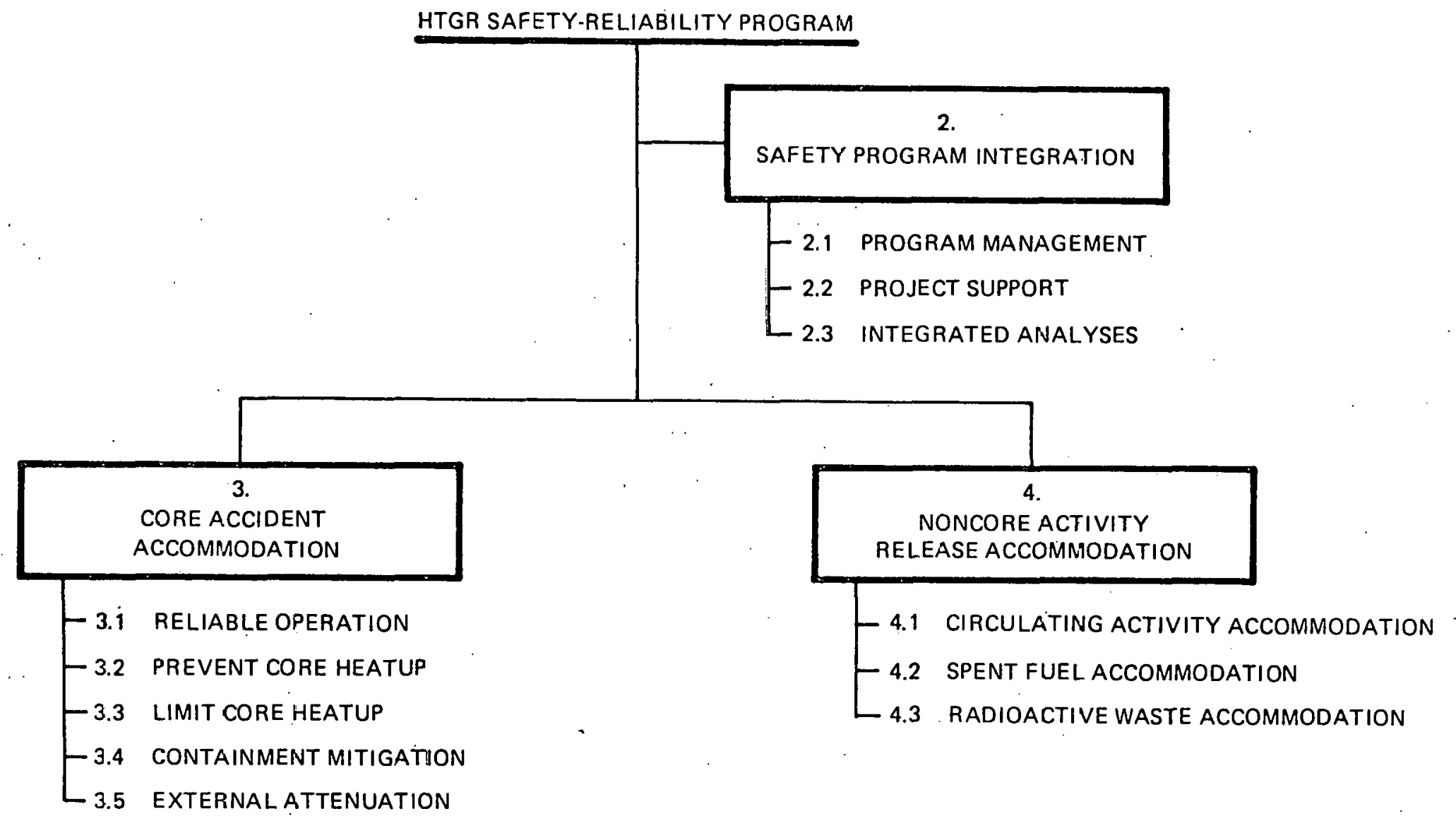

FIGURE 1-5. TOP LEVEL WORK BREAKDOWN STRUCTURE 


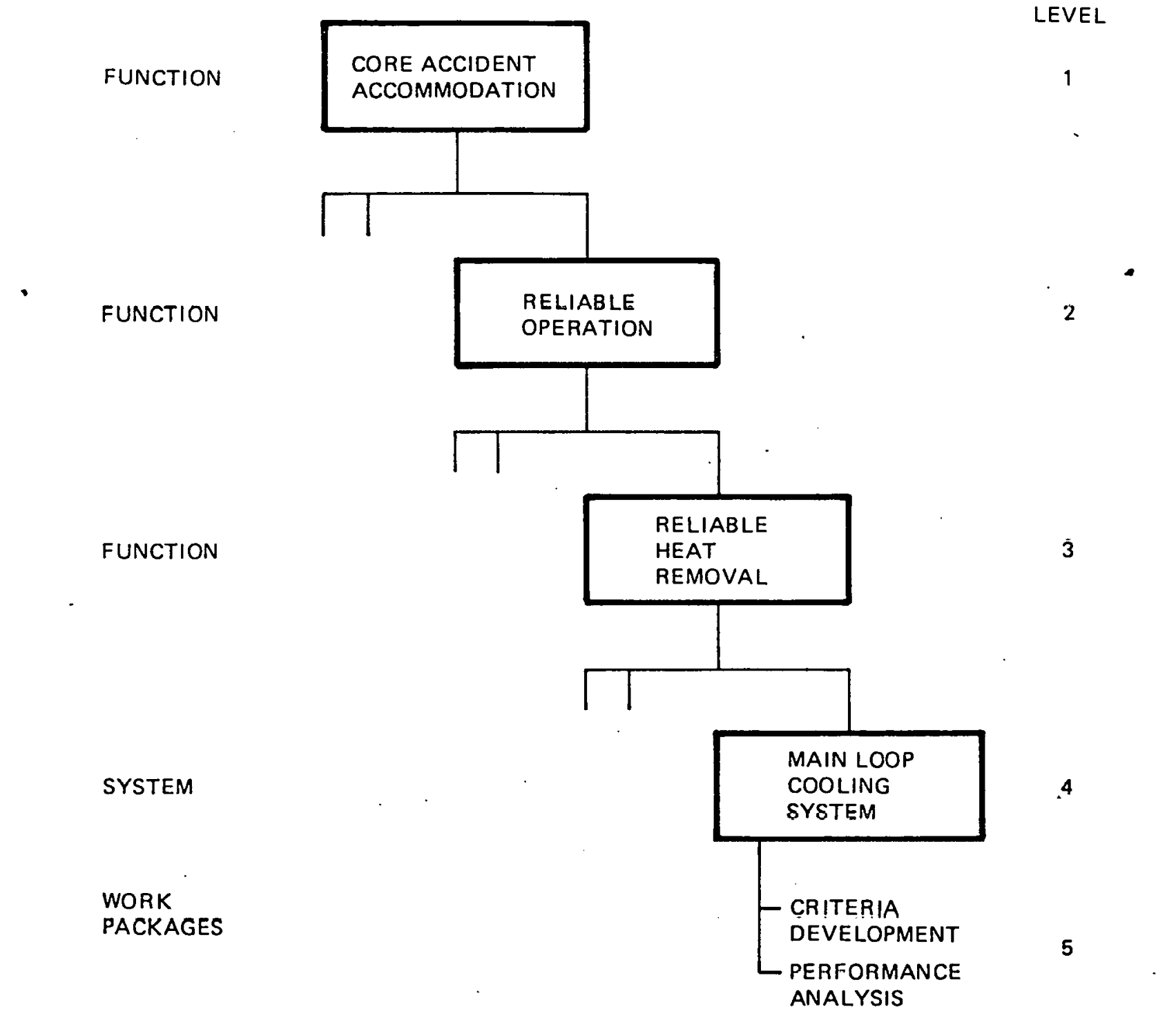

FIGURE 1-6. GENERALIZED WORK BREAKDOWN STRUCTURE SUBDIVISION 


\section{SAFETY PROGRAM INTEGRATION}

Objective: Ensure that all relevant HTGR safety characteristics are properly understood, provide the necessary support from and to the safety program into the design, licensing, construction, and operation of HTGR plants to confirm this understanding of safety characteristics.

A successful program requires harmony among the many internal tasks and with external programs. This task area provides the internal and external integrating tasks necessary to guide the overall safety-reliability program. As such, this task area assures that program goals and work packages are properly balanced. Figure 2-1 shows the task area breakdown.

\subsection{PROGRAM MANAGEMENT}

Objective: Provide all necessary technical management functions for the program.

To ensure a cost effective program, a clear program $\mathrm{plan}$ must be developed, the most important $R \& D$ activities must be identified within this plan and prioritized, and resources must be allocated to ensure activity completion. Additionally, major test facility requirements must be identified early to ensure supporting test data is provided and liaison activities need to be conducted to ensure maximum benefit from related research programs.

\subsubsection{Program Plan Development}

Objective: Develop and periodically update a comprehensive Safety-Reliability Program Plan.

Background and Issues: Program guidance is currently provided for the HTGR in a document entitled the "HTGR Program Summary Level Program Outline." This document is prepared and provided by GCRA to DOE on an annual fiscal year basis. This document identifies major program objectives and priorities and proposes a fiscal year budget resource allociliun. In turn, work proposed in this summary form represents a collection of work plans prepared and proposed by the individual HTGR program contractors, principally General Atomic Company, General Electric, Oak Ridge National Laboratory, Idaho National Engineering Laboratory, Bechtel Corporation and United Engineers and Constructors, Inc.

Critical safety-related research data requirements are currently identified in the individual HTGR Application Package documents (References 2-1 through 2-4) at a summary level. A fairly comprehensive tabulation of past licensing issues on the HTGR does exist (Reference 2-5). The AIPA study has been most instrumental in identifying key safety research areas for the HTGR (References 2-6 through 2-8). However, there exists currently no complete plan endorsed by DOE and GCRA which encompasses both short and long term objectives and 
which provides a framework of program continuity. That is the purpose of the plan provided herein.

Work Packages: To be identified.

\subsubsection{R\&D Prioritization}

Objectives: Establish the relative priorties of the R\&D work packages which reflect timing, funding, and overall program constraints:

Background and Issues: As described in the previous section, program priorities are currently identified by GCRA to DOE in the "HTGR Program Summary Level Program Outline." The priority decisions are not currently made on the basis of a formalized cost/benefit procedure, but rather reflect the judgment of program technical managers against varied objectives. GCRA is currently developing a management plan which includes a more formalized approach to prioritizing IITGR data needs. This approach should be integrated and supplemented as necessary by this task to determine safety work package priorities.

\section{Work Packages: To be identified.}

\subsubsection{Resource Allocation}

Objective: Determine the appropriate allocation of funding for the various safety program elements being conducted by contractors.

Background and Issues: Again, resource allocations are currently identified by GCRA to DOE in the "HTGR Program Summary Level Program Outl ine" on a year-to-year basis. Other. DOE nuclear programs have established Safety Technical Management Centers at the national laboratories to provide guidance on funding allocations to DOE. The purpose of this task will be to formalize the funding allocation process for the HTGR safety program.

Work Packages: To be identified.

\subsubsection{Test Facility Requirements}

Objective: Prepare the functional and test requirements for safety-related HTGR experiment projects.

Background and Issues: Test facilities may be required to provide experimental data to verify HTGR safety methods. These may be either dedicated or nondedicated safety test facilities or experiments. No specific safety test facilities are currently identified for the HTGR program. Clearly, however, safety and reliability-related test information will be required from HTGR facilities and experiments dedicated to other purposes.

Work Packages: To be defined. 


\subsubsection{Liaison}

Objective: Interface with industrial and research groups estab7ishing the direction of LMFBR, LWR, and foreign HTGR safety research programs to ensure maximum benefit to the U.S. HTGR safety program.

Background and Issues: Historically, the HTGR has established beachheads in a number of industrial organizations charged with the responsibility for developing standards for nuclear power plants. In particular, an ANS subcommittee of the ANS Standards Committee was formed, charged with the responsibility for developing standards for gas-cooled reactors. A number of gas-cooled specific safety criteria document scopes and drafts have been prepared, a major one being $\mathrm{N}-213$ on "Nuclear Safety Criteria for the Design of Stationary Gas-Cooled Reactor Plants" (Reference 2-9). Unfortunately, none of these documents received final subcommittee approval and after 1975, the subcommittee suspended operation.

With regard to safety research programs, there have been and continue to be a number of liaison activities between General Atomic and foreign HTGR programs, notably Great Britian, France, and the Federal Republic of Germany (FRG). Most recently, there has been close cooporation between General Atomic and national laboratories in the FRG. in conducting the HTGR-AIPA studies. An attempt has been made by DOE $\therefore$ recently to nationalize HTGR research cooperation with the FRG and other European governments under an umbrella agreement (Reference 2-10).

Contacts between U.S. LWR and LMFBR safety research programs have been less direct. A near term function of this task should be to establish more formal technical. exchanges with these programs via the respective Safety Technical Management Centers which have been formed.

Work Packages: To be defined.

\subsection{PROJECT SUPPORT}

Objective: Provide support as required in all safety-related areas of plant design and licensing of HTGR projects and design studies.

The HTGR safety-reliability program must support other HTGR program activities, particularly design and licensing activities. Except for the specific deliverables identified below, this task area provides support on an as-required basis.

\subsubsection{Design Criteria}

Objective: Provide support as required in all safety-related areas of HTGR plant design.

Background and Issues: This task is intended to provide the overall safety-related performance and reliability criteria for the HTGR design and to conduct design reviews to ensure compliance as necessary. This task is responsible for the preparations of top level, comprehensive 
criteria documents. Currentiy, these criteria are provided in the "Nuclear Safety Plant Specification" document (Reference 2-11). This document establishes the safety criteria for the design and analysis of the HTGR nuclear steam supply system (NSSS), establishes design basis accidents, and classifies systems, components, and structures of the NSSS with respect to importance to safety. Safety criteria for the balance-of-plant systems are generally contained in a balance-of-plant interface requi rements document (BOPR).

Work Packages: To be defined.

\subsubsection{Reliability Integration}

Objective: Establish methods for and provide support to the integration of reliability engineering techniques into HTGR design.

Background and Issues: The establishment of numerical rellablifty targets for HTGR systems as envisioned by this plan requires that administrative and technical methods be established which ensure and enforce the successtul achievement of these goals in the HTGR engineering process. While historically, methods have been identified by which the designer demonstrates the achievement of other performance criteria, formal methods have not been established for complying with reliability goals. Tasks, however, are currently underway to establish such a formal methodology (Reference 2-12). Related tasks on the GCFR program at General Atomic have also identified a methodology base in this area (References 2-13 and 2-14). Major reliability programs have similarly been proposed for the LMFBR program (Reference 2-15).

Work Packages: To be defined.

\subsubsection{Licensing Support}

Objective: Provide support as required to project efforts involved in the licensing or safety approval of HTGR plants.

Background and Issues: This task is intended to support the licensing or safety approval process of HTGR projects. It will provide appropriate analysis documentation for 1 icensing topical reports (LTRs), preliminary safety analysis reports (PSARs), final safety analysis reports (FSARs), and environmental reports. A brief history of past HTGR licensing is provided in Section 1.5.

Work Packages: To be defined.

\subsection{INTEGRATED ANALYSIS}

Objective: Perform integrated analysis to provide a balanced. perspective of HTGR safety.

This task area integrates technical methods and associated bases which cross the lines of protections and the other safety program elements and which must be established to support task management 
decision making. This task area includes the following tasks: risk assessment, critical structures integrity, support systems reliability, and external events accommodation.

\subsubsection{Risk Assessment}

Objective: Integrate the technical products of each LOP and other program elements to quantitatively assess HTGR risks.

Background and Issues: As described in Section 1.5, a program of applying probabilistic risk assessment methods in the study of the safety of HTGRs has been underway since 1974. Since its initiation, the study, entitled "Accident Initiation and Progression Analysis" (AIPA), has - compiled an extensive body of HTGR safety-related information, particularly on the steam cycle HTGR design. This task will continue to build on this body of knowledge employing and improving the AIPA methodology to provide a balanced HTGR safety perspective and to ensure the appropriate assignment of LOPS and LOP criterion, particularly for other HTGR applications.

Work Packages: To be defined.

\subsubsection{Critical Structures Integrity}

Objective: Ensure that HTGR critical structures support program reliabiity goals.

Background and Issues: The integrity of several HTGR structures is essential to the systems providing the line of protection functions. In particular, the critical structures are the reactor core, the prestressed concrete reactor vessel (PCRV) and internals, and the containment building. Each of these critical structures may support more than one line of protection. Therefore, to ensure the achievement of safety program goals, it is necessary to define criteria compatible with achieving lines of protection, reliability, and to assess the ability of these structures to meet these criteria in an integrated fashion.

Past licensing reviews have left open a number of issues with respect to the integrity of these critical structures. These past licensing issues are summarized below:

- Reactor Core and Core Support Integrity. The design criteria for graphite structures has not yet been completed or approved. A joint subcommittee of the American Concrete Institute and ASME has been formed to generate a code section for graphite. Many of the items before the subcommittee require experimental verification which will have to be obtained from the ongoing HTGR technology program. In particular, further research may be required to define the oxidation behavior of graphite at high temperatures in the presence of water vapor and metal carbonization effects due to impurities in the helium coolant. These effects are of even more concern in the higher core outlet temperature applications of the HTGR. 
- Primary Coolant System Integrity. A limiting design basis for the core auxiliary cooling systems and PCRV internals is the design basis depressurization accident which postulates a rapid depressurization of the PCRV. The leak size for this event depends upon what limiting primary coolant system break size must be postulated as occurring in the design probability range.

Relevant to this issue, the design bases for the design of the PCRV closures have not yet been approved by the NRC. Most closures are designed and fabricated to ASME Code, Section III, Division 1. LWRs are not required to assume failure of Class i pressure vessels for coolant system design basis; therefore, the General Atomic Company position is that the assumption of such failures for the HTGR is excessive and should not be considered for coolant system design. Some closures used for large heat exchanger cavities are made of prestressed concrete, designed and constructed to ASME Code, Section III, Division 2. Due to their redundant prestressing elements, General Atomic Company considers their gross failure to be so improbable as to preclude their failure as a coolant system design basis.

Another open issue in this area is the requirement for the possible in-service inspection (ISI) of the PCRV 1iner. General Atomic Company's current position is that a thermally insulated liner should not require ISI. This remains to be confirmed by the NRC.

The HTGR-GT and HTGR-R applications pose additional potential issues in this area. During normal operation of the HTGR-GT, large pressure differentials exist across the turbine and compressor sections of the turbomachine. A debladiting of the turbomachine would cause the collapse of this differential, leading to large pressure stresses on reactor internals. Preliminary analyses show that redesign of the core support posts, CACS components, and the core support structure might be required to accommodate such an event. The HTGR-R configurations include direct cycle concepts wherein hydrogen, methane, and carbon monoxide must be contained within the PCRV and containment. The containment of such potentially explosive gasos poces now issucs with rcspect to structural inleyrily design bases.

- Containment System Integrity. The AIPA analyses reported in Reference 2-7 conclude that the survivability of PCRV liner cooling is critical to preventing containment overpressurization failure from accident scenarios resulting in core heatup. A successfully cooled PCRV liner turns the core heatup around to the extent that thermally-induced PCRV concrete decomposition is prevented. This, in turn, prevents the generation of combustible and noncondensible gases which could lead to containment overpressurization. 
Critical to the survivability of the PCRV liner cooling system is the question of failure mode of the PCRV top head thermal barrier. The mode, failure temperature level, and associated timing of the thermal barrier and cover plates determines whether preferential exposure of one or two liner cooling tubes results in boilout causing liner cooling failure or whether sufficient liner cooling surface is exposed to remove core decay heat without boilout. Thermal barrier failure limits are also critical to the question of how long normal helium coolant system flowpath geometry can be maintained during an interuption of forced coolant flow. The temperature at which the cover plates would actually fail has not been experimentally determined and the analytical uncertainties with respect to thermal barrier failure modes is large.

In the AIPA studies to date, a failure model specifically for the prestressed HTGR containment building has not been formulated. Rather, reinforced containment models from the reactor safety study were assumed. The overpressure failure point of the containment is critical to determining the timing of radionuclide release and, hence, ability to ensure radionuclide removal mechanisms. Further, development of containment failure models would, therefore, appear beneficial.

Work Packages: To be defined.

\subsubsection{Support Systems Reliability}

Objective: Ensure the critical HTGR support systems support program reliability goals.

Background and Issues: The design of the reactor systems which provide the LOP functions requires the provision of auxiliary or support systems which service the primary system. In many cases, these support systems are necessary to the accomplishment of only one LOP function. In such cases, these systems are considered within the LOP which they support. In rarer cases, these systems support more than one LOP function and, therefore, require the integrated reliability treatment provided wilhin this task. If the analyses provided by this task do not clearly support the common usage of the se systems in achieving multiple LOP reliability, then means of providing the LOP function independent of the se support systems must be sought.

Two particular systems may be noted to cross LOP boundaries: the electric power system and the component and service cooling water systems. In the current HTGR design, $A C$ and $D C$ electrical power is necessary to support the operation of the main loop cooling system, the core auxiliary cooling system, the liner cooling system, and the containment air cleaning system, thus supporting the first four LOPs. Similarly, component and service cooling is required for heat removal in the main loop cooling system, core auxiliary cooling system, the liner cooling system, and potentialiy, the containment air cleaning system. 
The analysis of electric power reliability in Reference 2-7 shows that the assumed mean repair time of the offsite power source, assuming it is lost in the first place, is critical to establishing whether the overall safety-reliability goals are met. Allowing for a diesel system start failure of $2 \times 10^{-3}$ per demand as assessed in Reference 2-7, a probability of better than $5 \times 10^{-4}$ for the timely availability of other than emergency power sources must be assured to meet the cumulative objective of $10^{-6}$ for LOP 1 through LOP 4. This places a heavy reliance on systems external to the HTGR plant or on systems within the HTGR plant not designed as dedicated safety systems. Clearly, further research into this area of LOP dependency is required.

Detailed analysis of the common susceptability of HTGR systems to . component cooling or service water supplies has not been reported in AIPA studies to date. Studies of other reactor systems, however, have shown this dependency to be critical to achieving reliability objectives.

\section{Work Packages: To be defined.}

\subsubsection{External Events Accommodation}

Objective: Ensure that external events do not compromise the successful attainment of program reliability goals.

Background and Issues: Potential external forces include both natural and and man-made hazards. Severe external events such as 1 arge earthquakes, windstorms, floods, aircraft or turbine missles, fires, and explosions have the potential to cause common mode failure of plant

- equipment or structures, potentially violating the independence of the HTGR lines of protection. It is important that such external events be, therefore, considered in an integrated fashion and to establish necessary criteria to ensure program reliability goals can be obtained.

Possibly one of the most significant external forces in terms of potential common mode effects is a large earthquake. AIPA analyses reported in Reference 2-6 calculated the risk associated with the HTGR from earthquakes smaller and larger in magnitude than the safe shutdown earthquake. This analysis did not show that such events were particularly risk significant. This result, however, runs contrary to recent risk assessments completed on light-water reactor plants. In any case, there appears to be wide disagreement among experts as to the frequency and results of earthquake occurrences. Thus, the uncertainty of earthquake-induced risks must be considered large.

Unique to the HTGR is the question of the response of the graphite block core to a seismic event. NRC questions in this area have centered on the seismic design criteria and the seismic analysis methods to be used. This could remain an open licensing issue in the restart of any HTGR application review.

Unique to the HTGR-R application is the issue of chemically induced explosion or fire effects from nearby process storage sites affecting the risk envelope. Criteria need to be established which determine the minimum safe distance between the reactor and the gas storage facilities.

Work Packages: To be defined. 


\subsection{REFERENCES}

2-1 "High Temperature Gas Reactor Steam Cycle/Cogeneration Application Study," Gas-Cooled Reactor Associates, December 1980.

2-2 "High Temperature Gas Reactor Gas Turbine Application Study," Gas-Cooled Reactor Associates, December 1980.

2-3 "High Temperature Gas Reactor Reformer Application Study," Gas-Cooled Reactor Associates, December 1980.

2-4 "High Temperature Gas Reactor Nuclear Heat Source Demonstration Reactor Application Study," Gas-Cooled Reactor Associates, to be issued.

2-5 "Selection, Strategy Analysis, and Options for Resolution of Key HTGR-SC Licensing Issues," Target Technology Ltd., March 21, 1978.

2-6 "HTGR Accident Initiation and Progression Analysis Status Report," ERDA Report GA-A13617, V.I-VIII, General Atomic Company, October 1975 to January 1977.

2-7 "HTGR Accident Initiation and Progression Analysis Status Report - Phase II, Risk Assessment," DOE Report GA-A15000, General Atomic Company, Apri1 1978.

2-8 "Enhanced Safety Feature Ranking Study for the $900 \mathrm{MW}(\mathrm{e})$ HTGR-SC, "General Atomic Design Document 905009, August 15, 1980.

2-9 ANS N-213, "Nuclear Safety Criteria for the Design of Stationary Gas-Cooled Reactor Plants," (Draft).

2-10 U.S.-Federal Republic of Germany Umbrella agreement.

2-11 Nuclear Safety Plant Specification - HTGR GT Two-Loop Plant," GA Document 904209, November 6, 1979. (Criteria for other HTGR-Applications are scheduled to be issued by Apri1. 1981).

2-12 Method for Choosing Reliability Criteria," GA Document. 905079, August 25, 1980.

2-13 Reilly, 0. T., "A Review of Methods for the Integration of Reliability and Design Engineering," DOE report GA-A14748, General Atomic Company, March 1978.

2-14 "GCFR Plant Specification for Reliability," General Atomic unpubli shed data, September 9, 1980.

2-15 "Safe Shutdown Reliability Program Plan for Large Breeders," USDOE Draft Report, May 1978. 


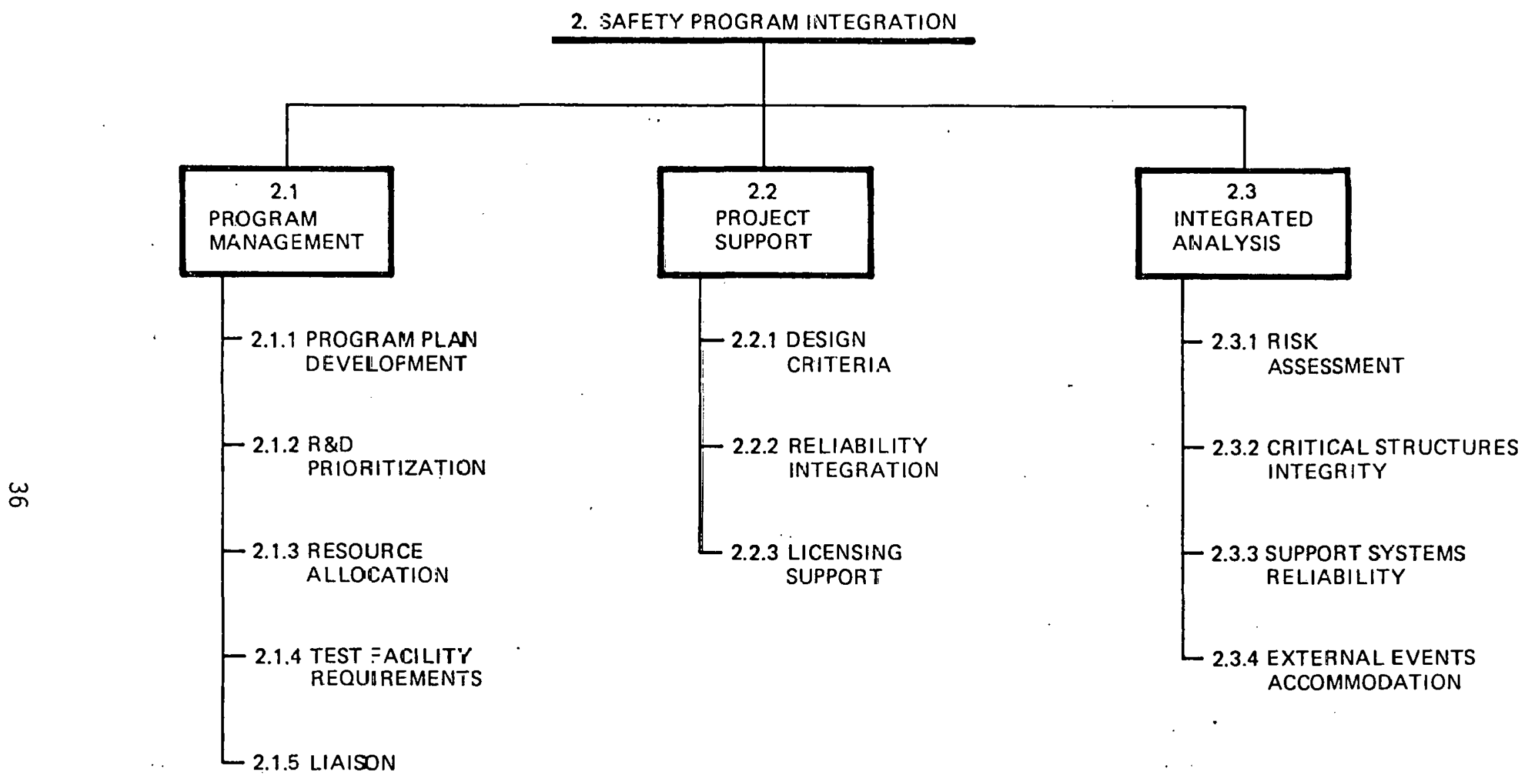

FIGURE 2-1. TAŠK 2 SAFETY PROGRAM INTEGRATION PREA BREAKCOWN 
3. CORE ACCIDENT ACCOMMODATION

Objective: Develop a technology base to support five lines of protection for the pubTic which limit the risks of HTGR core heatup accidents.

The five lines of protection (LCPs) defend against HTGR core heatup accidents. LOPs 1 and 2 deal with engineering features provided to prevent core heatup while LOPS 3 to 5 are dedicated to accident mitigation. Thus the LOPs separate the core heatup sequence into its major components; each LOP serves to independently reduce the probability and consequence, hence risk, of the core heatup accident sequence.

LOPs 1 and 2 act to prevent core fuel particle failures, hence the radiological consequences associated with LOP 1 and 2 success are small. Indeed, economic criteria (i.e., preventing plant damage) are likely to be more limiting for these two LOPs than the identified safety consequence criteria. Therefore, the accident prevention portion of the program reduces primarily to a reliability assurance program.

LOPs 3 to 5 , however, mitigate accidents which involve core heatup and radionuclide release from the core. Here, safety consequence criteria are limiting. Thus, the accident mitigation portion of the plan emphasizes consequence-related research and development. Figure 3-1 shows the task area breakdown.

\subsection{RELIABLE CPERATION (LOP 1)}

Objective: Demonstrate that the systems provided in the HTGR for normal eletrical power and/or process heat generation prevent, with high reliability, the initiation of events requiring safety systems actuation. (Proposed goal: $10^{-1 / y r)}$

The normal operating systems provided in the HTGR are an important contributor to overall HTGR safety. These systems provide a barrier against a too-frequent demand for the dedicated safety systems, hence reducing the probability of initators which could lead to. a core heatup.

The operating systems satisfy a dual role: (1) economic electrical power generation and (2) a first means of reactor shutdown/cooldown following the occurrence of offnormal events. In either case, however, the operating systems must provide two functions reliably: core heat removal and reactor and plant control.

\subsubsection{Reliable Heat Removal}

Objective: Demonstrate that the systems provided in the HTGR for normal electrical power and/or process heat generation provide reliable core heat removal. 
Background and Issues: In all the HTGR applications currently studied, heat is transferred from the reactor core to a heat exchanger or steam generator via the forced convection of pressurized helium. In HTGR-SC, HTGR-PS/C, and HTGR-R designs primary helium flow is ensured by motor-driven circulators. In the HTGR-GT design, helium flow is ensured by gas turbine compressors. Heat transferred into the primary heat exchanger is transferred to produce electrical power or process heat and waste heat rejected to the ultimate heat sink by varying means. In all

- cases, this main loop cooling system coupled with the associated power or heat conversion system provides a first means of reactor heat removal even after reactor shutdown. In general, components employed to accomp"lish this heat removal function are not designated as safety class components and, historically, safety-related reliability crịteria have not been imposed on these systems.

To date, only the HTGR-SC main loop cooling system has been subjected to a detailed reliability analysis as part of the AIPA Study (Reference $3-1$ ). The main loop cooling system (MLCS) design analyzed in this study was the $3,000 \mathrm{MW}(t)$ reference HTGR design as it existed in 1975. The power conversion system provided in this design was of a conventional type provided by Gilbert Associates. The system was analyzed to develop a fault tree of failures leading to a top event of "Loss - of Main Loop Cooling Demanding CACS." A cummulative median failure probability of approximately $3 \times 10^{-1}$ per year was then assessed for this event, principally due to loss of the probability of secondary coolant heat sink (i.e., loss of condenser vacuum.) Ten percent of this failure probability was assessed to involve an immediate outage of the MLCS function, with the remaining $90 \%$ involving a delayed failure allowing some time for repair or other operator action.

Recently, the AIPA Phase II results were adjusted to account for the unique design features of the $900 \mathrm{MW}(\mathrm{e})$ HTGR-SC plant (Reference 3-2). Due to a change in the $900 \mathrm{MW}(\mathrm{e})$ design, the boiler feedpumps cannot operate against atmospheric backpressure. This change results in an increase in events involving an immediate outage of the MLCS (from 10\% to $90 \%$ ).

The above discussed results indicate that the HTGR-MLCS designs provided to date are marginal in their ability to support an LOP 1 reliability of $10^{-1}$ per reactor year. This is not surprising in that traditionally, the safety role of these systems has been neglected. Further reliability analysis, criteria, and potential reliability improvements clearly need to be conducted for these systems.

Work Packages: To be defined.

3.1.2 Reliable Plant Control

Objective: Demonstrate that the systems provided in the HTGR for normal electrical power and/or process heat generation provide reliable reactor control. 
Background and Issues: The HTGR system is designed so that in the power operating range the net effect of the prompt inherent nuclear feedback characteristics compensates for externally initiated reactivity transients. The inherent operating characteristics of the system are supplemented with engineered control and instrumentation systems.

The plant control system (PCS) provides for automatic plant operation by regulating reactor power and controlling other key process variables. The system also provides automatic actions for the protection of major components and provides a first line of defense against incidents which would result in the need for the plant protection system.

The plant data acquisition, processing, and display system (DAP) provides a nonsafety-related interface. between plant instrumentation and the plant operator. The system provides the plant operator with information that will increase efficiency in operating the plant, will protect plant equipment, and will warn the operator of equipment degradation through the annunciation of alarm conditions.

Finally, the human operator forms part of the LOP 1 plant control function. The operator's ability to operate the plant in an error-free manner and anticipate and head off plant problems before automatic protection functions are required contributes significantly to the overall plant reliability.

The overall contribution of the systems identified above to supporting the LOP ? reliability goal has not been quantified to date. More study of this area is required, particularly as the design of these systems progresses. Some of the HTGR applications, notably the HTGR-GT's direct cycle system, pose unique problems with regard to plant control reliability.

Work Packages: To be defined.

\subsection{PREVENT CORE HEATUP (LOP 2)}

Objective: Demonstrate that the dedicated safety systems provided in the HTGR prevent the occurrence of a core heatup with very high reliability, given a failure of LOP T systems.

(Proposed goal: <10-3/demand)

The dedicated safety systems provided in the HTGR design to prevent core heatup have traditionally provided the most important contribution to minimizing accident risks. These systems provide a barrier against heatup of the core which could result in radionuclide release from the fuel particles, allowing for the failure of LOP 1 systems and for certain structural and external events. Two functions must be performed by these systems with high reliability: shut down the reactor chain reaction and removal of the reactor residual and decay heat. 


\subsubsection{Reliable Shutdown Heat Removal}

Objective: Demonstrate that the dedicated safety systems provide very reliable shutdown heat removal.

Background and Issues: In all the HTGR applications currently studied, the safety-class shutdown heat removal function is provided by the core auxiliary cooling system (CACS). The CACS, installed in peripheral cavities within the PCRV, consists of two or three auxiliary coolant loops, each having a variable speed electric induction motordriven auxiliary circulator, an auxiliary shutoff valve, and a watercooled heat exchanger. A pressurized water system provides heat removal from the core auxiliary heat exchanger to cooling towers, and thus, to the ultimate heat sink, ambient air. The CACS is designed to provide its heat removal function with the primary system pressurized or depressurized.

The CACS, from a reliability point of view, has possibly received more study than any other HTGR system. Besides numerous internal studies at $\mathrm{LA}$, Joloman has done a reliability study of the system (Reference 3-3). Considering the GCFR 1iterature (References 3-4, 3-5, and 3-6) additional studies of an almost identical system may be found.

The HTGR-AIPA Study (Reference 3-1) reports an assessment of both the start and running reliability of the CACS for a 3,000 MW( $t)$ reference HTGR. The median start failure probability is assessed as $3 \times 10^{-4 *}$ per demand, which is in good agreement with other studies. The running failure probability for reasonable mission times is slightly smaller. The CACS design tends to be so redundant that the assessed failure probability is highly dependent on what common cause failure rate is assumed.

Based upon current reliability assessments and designs, the CACS appears to support the proposed LOP 2 goal of $10^{-3}$ per demand. Since the Fort St. Vrain HTGR design does not include a CACS, it will be important to consider ways in which the HIGR R\&D program can confirm the calculated reliabilities. This is consistent with NRC review of the Fulton and Summit HTGR-CACS designs which concluded that the CACS circulators and shutoff valves are prototypical items which deserve special testing programs and that CACS testing criteria must be developed for preoperational design verification and on-iine testing.

Work Packages: To be defined.

\subsubsection{Reliable Reactor Shutdown}

Objective: Demonstrate that the dedicated safety systems provide very reliable, automatic reactor shutdown.

*Given that support systems are available, particularly electrical power (these support systems are treated under Task 2.3.3). 
Background and Issues: The primary reactor shutdown function in the HTGR is accomplished by gravity drop of control rods through channels in the fuel element graphite blocks. Initiation of this trip function is accomplished by the plant protection system (PPS). The PPS prevents unacceptable release of radioactivity by initiating automatic actions that protect the fission product barriers. Besides initiating reactor trip, the PPS initiates the CACS, initiates containment isolation, and provides isolation functions on systems containing high energy fluids.

The reactor shutdown reliability has been assessed as part of the AIPA Study (Reference 3-1). A complete analysis of the Fort St. Vrain HTGR scram systems has also been performed by Kaman Sciences Corporation (Reference 3-7).

The AIPA analysis assessed the automatic reactor trip median failure prbability as $10^{-5}$ per demand, well below the LOP 2 target failure probability. There, therefore, appear to be no key safety issues associated with this LOP 2 function.

Work Packages: To be defined.

\subsection{LIMIT CORE HEATUP (LOP 3)}

Objective: Demonstrate that the response of the reactor system will inherently restrict core heatup and prevent a consequential threat to radionuclide containment even in the event of LOP 1 and 2 faiture.

(Proposed goal: $<10^{-1}$ per demand)

The response of the HTGR core to a heatup event resulting from failures of the LOP 1 and 2 functions is inherently slow. This allows ample time to consider and implement mechanisms to limit the core heatup such that even if substantial core radionuclide release occurs, radio- : nuclide containment by the other barriers (i.e., PCRV and containment): are not consequentialiy threatened. Based upon the two functions which: can fail leading to the need for LOP 3 protection, two LOP 3 functions must be provided: shutdown heat removal fault accommodation and reactor shutdown fault accommodation.

\subsubsection{Heat Removal Fault Accommodation}

Objective: Demonstrate that even if shutdown heat removal functions cannot be accomplished by the MLCS and CACS, the core heatup transient can be Timited to prevent consequential containment failure.

Background and Issues: The HTGR design is unique compared to liquid cooled reactors in having a cooled primary coolant boundary liner. This cooled liner inherently provides a third heat sink within the PCRV for the removal of reactor shutdown heat principally via radiative heat transfer. For smaller reactor cores, such as the Fort St. Vrain HTGR, the liner cooling system (LCS) has the ability to remove enough core heat to prevent core radionuclide release even in the event of a loss of forced circulation. For larger plants, the LCS, as currently configured, 
does not have the capability to turn the core heatup around to the point of preventing substantial fuel particle failure. However, even for larger plants LCS operation can prevent PCRV concrete heatup to the point of decomposition and thus maintaion gross PCRV integrity. This protecton of PCRV integrity, in turn, protects the containment building from any consequential threats of PCRV concrete decomposition (and associated flammable and noncondensible gas generation) or structural failures.

The AIPA analysis of a heatup event for a large HTGR core identifies the failure mode of the top head thermal barrier as being critical to the success of the liner cooling function. One thermal barrier failure mode that can be postulated is failure of a sufficient number of components (cover plates; seal sheets, and insulation mats) to expose the LCS surface to the high temperatures in the upper plenum of the core cavity. If this occurs, the rate of heat removal by the LCS exceeds the reactor decay heat generation rate such that the temperature transient is "turned around," and additional damage to PCRV components is prevented. On the other hand, if thermal barrier seal sheets fail in a particular sequence that results in the preferential exposure of one or two LCS tubes, boilout of the the tubes would occur and LCS failure could result. Based upon a statistical treatment of an assumed random failure behavior of the thermal barrier sheets, the AIPA Study estimated the probability of LCS function failure at $10^{-1}$. However, the uncertainty on this estimate

- was large, with a..9 probability being the estimated upper bound. $\rightarrow$

Other causes of LCS failure were al so identified. Notably, electric power is required to operate the LCS motor-driven pumps and valves. Thus, for sequences involving loss of electrical power, this electrical dependence formed another higher order failure probability path for the LCS LOP 3 function.

General Atomic Company is currently investigating ways of improving the LOP 3 capability. Means identified include enhanced liner cooling heat removal capability, providing radiation holes in the core to promote heat transfer from the core center, and designing for primary helium side natural convection to remove heat. These areas of investigation require further consideration to ensure that the LOP 3 function can be reliably achieved.

Work Packages: To be defined.

\subsubsection{Reactor Shutdown Fault Accommodation}

Objective: Demonstrate that even if automatic reactor shutdown functions cannot be accomplished by the PPS and control rod system, the nuclear chain reaction can be terminated to limit core heatup.

Background and Issues: The HTGR design includes an emergency shutdown system capable of injecting small neutron absorbing balls into core cavities to shut down the reactor in the event the automatic control rod trip function fails. This reserve shutdown system (RSS) is manually initiated by the plant operator. 
The AIPA Study (Reference 3-1) assessed the failure probability of the RSS and determined that it was dominated by failure of the operator to initiate the system. The slow heatup of the reactor core allows the operator approximately 1-1/2 hours to recognize scram system failure and initiate the RSS. Based on this time period, the AIPA Study estimated the median RSS failure probability as $10^{-3}$ per demand; well below the target probability for the LOP 3 function.

It should be recognized that the LOP 3 function studied in this task

$\therefore$ represents the accommodation of anticipated transients without scram (ATWS). This issue currently is an unresolved licensing and design issue for light-water reactor plants. The resolution of this issue on LWRs may play an important role in influencing the course to be taken on the HTGR in this area.

Work Packages: To be defined.

3.4 CONTAINMENT MITIGATION (LOP 4)

Objective: Demonstrate that containment system integrity is maintained to delay and limit the release of radionuclides even in the event of an unrestricted core heatup resulting from failures of the first three LOPs. (Proposed goal: $<10^{-12} /$ demand)

LOP 4 evaluates the containment building as a barrier which can successfully delay and limit the release of activity to the environment.: for accident sequences which fail the first three LOPs. Two major considerations are involved here: containment atmosphere response threats to containment integrity and radionuclide removal mechanisms within the containment.

\subsubsection{Containment Atmosphere Response}

Objective: Demonstrate that containment failure resulting from failures of the first three LOPs is either prevented or substantially delayed to allow time for radionuclide removal mechanisms to limit releases.

Background and Issues: Containment integrity may be violated either by failure to close the containment isolation valves or as a direct consequence of the heat liberated from an unrestricted core heatup event. In the latter case the potential mechanisms which could cause containment failure include direct thermal assault of the containment liner by hot helium jets or by fission product plateout, missile generation from the PCRV if structural failures occur at pressure, static overpressurization due to heating of the containment atmosphere or the generation of noncondensible gases, and dynamic overpressurization due to chemical explosions of combustible gases.

The AIPA study (Reference 3-1) and the HTGR safety research task on containment atmosphere response (CAR) (Reference 3-8) have addressed each of the above mechanisms: In all the core heatup sequences considered, 
the PCRV blows down to the containment atmosphere due to eventual failure of the PCRV relief valves. The CARS study has addressed the containment integrity issue following initial primary coolant blowdown and local heating of exposed structures (e.g., the containment liner). It was shown that shock waves originated by sudden primary coolant system blowdown do not create a hazardous condition for the containment structure. The study also analyzed the behavior of turbulent jets emanating from the PCRV and local heating of the containment liner due to jet impurgement. Bounding analyses indicated no significant probability of containment liner buckling due to these phenomena. Peak pressures and temperatures of the gases mixing in the containment atmosphere also caused no significant probability of containment failure.

After blowdown, the exchange of gases between the containment and the PCRV is minimal and dominated by PCRV expansion flow outward as core temperatures increase. If the core heatup is unrestricted and no 1 iner cooling is provided, heatup of the PCRV concrete begins, leading t.n eventual concrete decomposition and the liberation of $\mathrm{CO}_{2}$ and $\mathrm{H}_{2} \mathrm{O}$. CO and $\mathrm{H}_{2}$ gases may also be produced from reaction of the $\mathrm{H}_{2} \mathrm{O}$ with core graphite. Two modes of containment overpressurization may be associated with the gases which are liberated when concrete degradation occurs: (1) gas burning if no action is taken to inert the containment atmosphere and if an ignition source is present, and (2) gas accumulation if gas burning does not occur. For the former case, it is estimated that the containment failure pressure is reached and exceeded at approximately 143 hours, with an upper bound of 93 hours. In the latter case containment overpressure occurs in approximately 238 hours, with an upper bound of 188 hours. In either case there appears to be a substantial period (i.e., days) for radionuclide removal mechanisms to be active, al though containment is assumed to ultimately fail with a unity probability.

The AIPA study also assessed the failure probability of containment isolation. The assessed median failure probability for this function is $10^{-4}$ per demand.

It should be cautioned that the AIPA study did not consider the core heatup effects of sequences where the reactor cannot be shut down. A complete treatment of LOP 1 to 3 failure conditions would require accommodation of the consequences of such an event as well.

\section{Work Packages: To be defined.}

\subsubsection{Radionuclide Removal}

Objective: Demonstrate that removal mechanisms within the containment are effective in limiting the amount of radioactivity which is released to the environment.

Bar.kgrnund and Issues: The mechanisms available in the HTGR containment to reduce the airborne radionuclide concentration include both natural and engineered factors. Naturally occurring mechanisms 
include radioactive decay, coated surface sorption, water vapor-driven condensation, and gravitational settling. The engineered removal mechanism is an in-containment recirculating filtration system. Each of these mechanisms has differing effectivities with respect to the chemical form of the radionuclide in question. For example, the radioactive noble gases are largely unaffected by all the above mechanisms except for radioactive decay.

The AIPA study (Reference 3-1) addressed containment removal mechanisms for three basic chemical forms, the noble gases, volatiles (especially iodine), and solids (in aerosol form). Significant natural removal mechanisms were identified for iodine, particularly by steam condensation effects. A limiting uncertainty with respect to iodine removal is its chemical form within the containment atmosphere. Organic iodides plate out slowly and are more difficult to clean up. The AIPA study assumed a median estimate of $1 \%$ organic iodine formation based upon light-water reactor projections. This assumption requires further confirmation. Indeed, the question of chemical forms of iodine in post-accident containment atmospheres is currently a hotly contested light-water reactor issue.

Solid particulates are assessed to be removed significantly by both gravitational settling and by the recirculating filter system. In the... former case, settling decay constants compatable with those assessed for LWRs are assumed. The probability of filter system failure is also assessed, based upon failure probabilities of individual components. Again, the filter system failure probability is particularly dominated by sequences involving loss of electrical power to supply the fan motors.

Based upon the AIPA calculations, even with eventual containment failure, the removal of radionuclides is significant. Based upon initial radionuclide inventories, only $50 \%$ of $\mathrm{Xe}-133,1 \%$ of $\mathrm{I}-131$, and $.06 \%$ of CS-134 is released to the environment. These may be compared with the Reactor Safety Study (Reference 3-9) of LWR releases from containment of $90 \%$ of $\mathrm{Xe}-133,70 \%$ of $\mathrm{I}-131$, and $40 \%$ of $\mathrm{CS}-134$. Further work may be required to substantiate such substantial release differences.

\section{Work Packages: To be defined.}

\subsection{EXTERNAL ATTENUATION (LOP 5)}

Objective: Demonstrate that naturally occurring external attenuation mechanisms coupled with siting and emergency procedures precautions 7 imit the quantity of radionuclides which can be transported from the core fuel to the public even in the event of LOP 1 to 4 failure.

The function of LOP 5 is to show that both naturally occurring and external engineered attenuation mechanisms serve to limit the quantity of radioactivity which can be transported through the environment and to the public. Two areas of investigation are identified: natural attenuation mechanisms and siting and emergency procedures planning. 


\subsubsection{Natural Attenuation}

Objective: Verify that inherent attenuation mechanisms substantially limit radiological releases to the environment and the ensuing radiological consequences.

Background and Issues: Naturally occurring mechanisms of radioactive material fallout, decay in transport, and atmospheric dispersion effects can act to significantly alleviate the potential consequences. of a radionuclide release. These mechanisms were addressed in the HTGR-AIPA study (Reference 3-1) using models which were essentially the same as those employed in the Reactor Safety Study (Reference 3-9). It is anticipated that the adaption of analytical methods developed for other programs will satisfactorily serve the HTGR task identified here.

Work Packages: To be defined.

\subsubsection{Siting and Emergency Procedures}

Objective: Demonstrate that engineered precautions invoiving HTGR siting and emergency procedures can be taken to further mitigate the consequences of radiological releases.

Background and Issues: Historically, Title 10 to the Code of Federal Regulations, Part 100, has provided the criteria for siting with respect to accident radionuclide releases. Recently, however, the NRC has reevaluated this siting policy on the basis of considerations of class 9 (LWR core melt) accidents. Remote siting recommendations for nuclear reactors to reduce potential public risks have been made by the Siting Policy Task Force of the USNRC (Reference 3-10). The outcome of this siting policy review may significantly influence the HTGR research requirements in this area.

Reference 3-11 considers the need for remote siting of HTGRs in comparison to light water reactors, and concludes that, based upon HTGR inherent characteristics, the final siting rule should explicitly declare nonapplicability to HTGRs. Further work needs to be done along this line to establish siting and emergency planning requirements specifically for the HTGR. In particular, a limiting siting event compatable with LOP 5 assumptions and with the class 9 events identified in the Reactor Safety Study needs to be identified and defended. All the limiting accidents for which radiological consequences are identified in the AIPA study involve some attenuation due to the action of active systems (i.e., liner cooling heat removal, containment air cleanup system operation, etc.). Thus, the radiological consequences associated solely with inherent features of the HTGR cannot be identified.

Work Packages: To be defined. 


\subsection{REFERENCES}

3-1 "HTGR Accident Initiation and Progression Analysis Status Report - Phase II Risk Assessment," DOE Report GA-A15000, General Atomic Company, April 1978.

3-2 "Tranformation of AIPA. Phase II Results to the $900 \mathrm{MW}(\mathrm{e})$ SC Plant," GA Document 904438, February 22, 1980.

3-3 Solomon, K. A., D. 0. Krent, and W. E. Kastenberg, "A Prediction of the Reliability of the Core Auxiliary Cooling System for a High-Temperature Gas-Cooled Reactor (HTGR)," UCLA-ENG-7495, Januäry 1975.

3-4 Kelley, A. P. and T. Taniguchi, "A Reliability Analysis of the Residual Heat Removal Systems for a 300 MW(e) GCFR," DOE Report GA-A14653, General Atomic Company, January 1978.

3-5 Taniguchi, T and P. H. Raabe, "Reliability Studies for the Gas- Cooled Fast Breeder Reactor Residual Heat Removal Systems," DOE Report GA-A15420 (Vols. I and II), General Atomic Company, September 1980.

3-6 DeLaquil, P. III, "An Accident Probability Analysis and Design Eval - uation of the Gas-Cooled Fast Breeder Demonstration Plant," Massachusetts Institute of Technology Report MITNE-184, January 1976.

3-7 Becar, N. J., G. B. Cortis and D. E. Wood, "Reliability Analysis of an HTGR Scram System Including Human Interfaces,": EROA Report KSC-1037-1, Kaman Sciences Corporation, March 1975.

3-8 Landoni, J. A., et al, "Containment Atmosphere Response (CAR) Program Interim Summary Report," General Atomic Company GA-A14262, May 1977.

3-9 "Reactor Safety Study - An Assessment of Accident Risks in U.S. Commercial Nuclear Power Plants," USNRC WASH-1400 (NUREG 75/014), October 1975.

3-10 "Report of the Siting Policy Task Force," USNRC, Office of Nuclear Reactor Regulation, Report NUREG-0625, August 1979.

3-11 Borse11, A. W., F. S. Dombeck, and D. D. Orvis, "Reactor Siting Risk Comparisons Related to Recommendations of NUREG-0625," DOE Report GA-A16084, General Atomic Company, November 1980. 


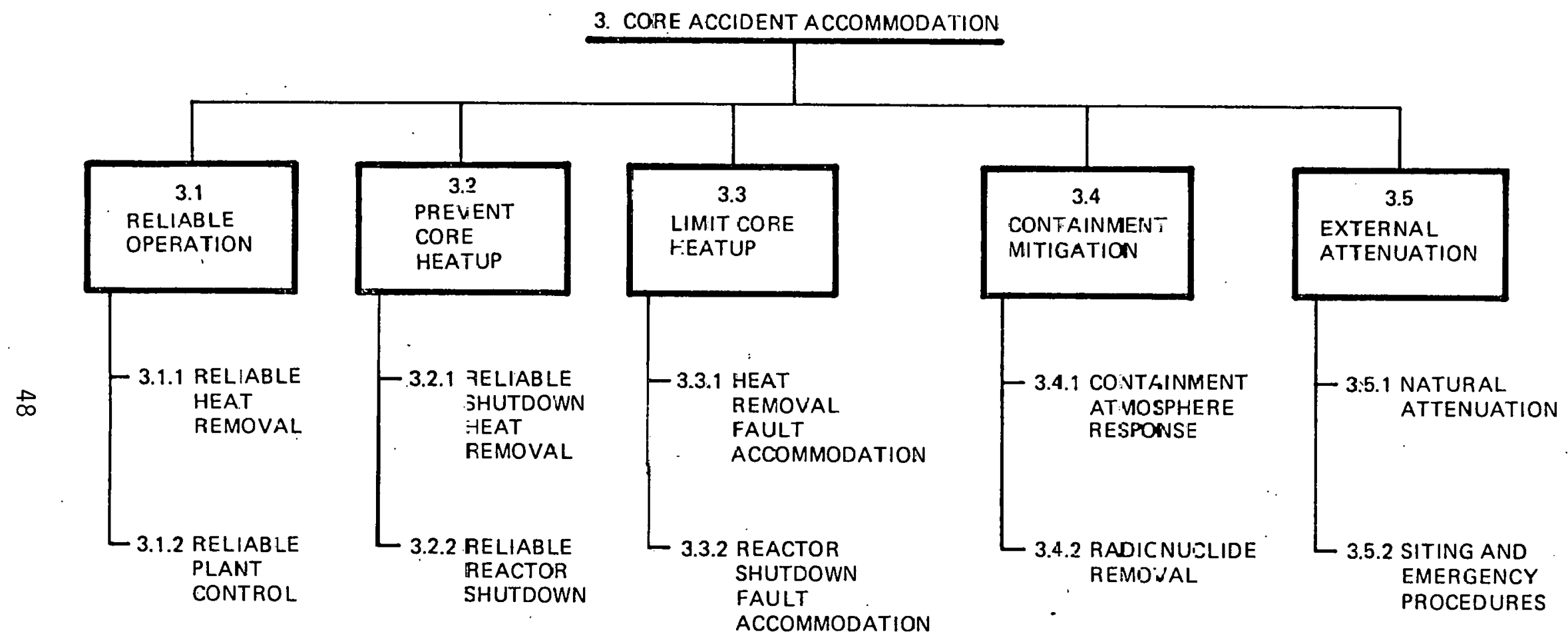

FIGURE 3-1. TASK ミ CORE ACCIDENT ACCOMMODATION AREA BREAKDOWN 


\section{NONCORE ACTIVITY RELEASE ACCOMMODATION}

Objective: Demonstrate that noncore radioactivity sites in the HTGR plant do not pose an unacceptable risk to the public health and safety. (Proposed Risk Envelope defined in Section 1.)

The hazard from excore activity sources is generally accepted not to constitute a dominant risk relative to the core activity. However, these sites of smaller activity releases might dominate the high frequency risk which is concerned with activity releases that are reasonably likely to occur during the plant lifetime. Therefore, release mechanisms for these excore sources of activity should be considered to assure that the risk 1 imit envelope is met over the entire frequency spectrum.

This task area is broken down consistent with the sites of activity in the HTGR plant other than the reactor core. These sites are: activity circulating in reactor system fluids, activity in spent fuel, and radioactive gaseous, liquid, and solid wastes. Figure 4-1 shows the task area breakdown.

\subsection{CIRCULATING ACTIVITY ACCOMMODATION}

Objective: Demonstrate that activity normally circulating in HTGR fluid systems does not pose an unacceptable risk to the public health and safety.

Background and Issues: Two major fluid systems in the HTGR contain small amounts of circutating activity: the primary coolant system and the secondary coolant system.

The secondary coolant in the main steam, reheat steam, and feedwater system contains small amounts of tritium and may have traces of fission products. The principal barriers to release of the secondary system activity include relief and isolation valves, fluid piping, primary heat exchangers, turbine, condenser, air ejectors, and miscellaneous tanks and heat exchangers.

The principal barrier to circulating activity within the primary helium coolant is the liner of the PCRV. Other portions of the primary coolant barrier are the PCRV closures, small pipes (including two relief trains) and instrument lines, and heat exchangers. Additionally, a helium purification system is provided to maintain a very low continuous circulating activity level.

The first phase of the HTGR-AIPA study (Reference 4-1) addressed the risks from accidents affecting all the radionuclide sources in an HTGR plant. With the exception of reheater tube leaks, the circulating activity sources were shown to be either of negligible consequence, or of sufficiently low probability to be bounded by the risk of other events. Reheater tube leaks, however, defined the risk envelope in the low consequence end of the accident spectrum. Since the time of this study, 
helium-to-steam reheating has been eliminated from the HTGR-SC concept thus eliminating this relatively higher risk event. Other HTGR applications wi11, however, have to be assessed with respect to circulating activity releases.

\section{Work Packages: To be defined.}

\subsection{SPENT FUEL ACCOMMODATION}

Objective: Demonstrate that activity contained in spent HTGR fuel does not pose an unacceptable risk to the public health and safety.

Background and Issues: A not inconsiderable source of radioactivity. is found in the fuel blocks that are removed from the core during refueling. Protection of the blocks within the power plant during handling and storage involves many protective barricrs and ventilation control systems.

The HTGR-AIPA studied, as a representative initiating event for this activity source, the drop of a fuel shipping container. Risks from this event were shown to be negligible.

Work Packages: To be defined.

\subsection{RADIOACTIVE WASTE ACCOMMODATION}

Objective: Demonstrate that activity contained in radioactive wastes generated by the HTGR plant does not pose an unacceptable risk to the public health and safety.

Background and Issues: The three forms of radioactive waste produced from the operation of the HTGR plant are gaseous, liquid, and solid.

Most of the gaseous waste in the power plant is handled in the helium purification system within the top head of the PCRV. This area is within the containment and, therefore, has multiple barriers of protection. Some of the traps for fission products are regenerated at intervals, and at this time, some of the fission products and tritium are circulated outside of the containment and are temporarily stored in a gas waste tank.

There is very little liquid waste in an HTGR power plant due to the use of a gas as primary coolant. The greatest concentration of liquid wastes would occur from accidents such as steam leaks causing dump of a steam generator. The dumped water is then processed by a liquid waste system wherein the principal liquid waste concentration occurs.

The amount of solid waste associated with an HTGR is also small. Sources include contaminated gloves, towels, and other maintenance items. The largest solid activity site is the high temperature filter absorber employed in the helium purification system. This filter is 
removed and replaced with a fresh unit at intervals. The spent filter is then stored for radioactive decay and subsequently shipped offsite.

All of the above radioactive waste categories were considered in the Phase I AIPA study. Risks from releases of this material were shown to be negligible.

Work Packages: To be defined.

\subsection{REFERENCES}

4-1 "HTGR Accident Initiation and Progression Analysis Status Report," ERDA Report GA-A13617, V.I-VIII, General Atomic Company, October 1975 to January 1977. 


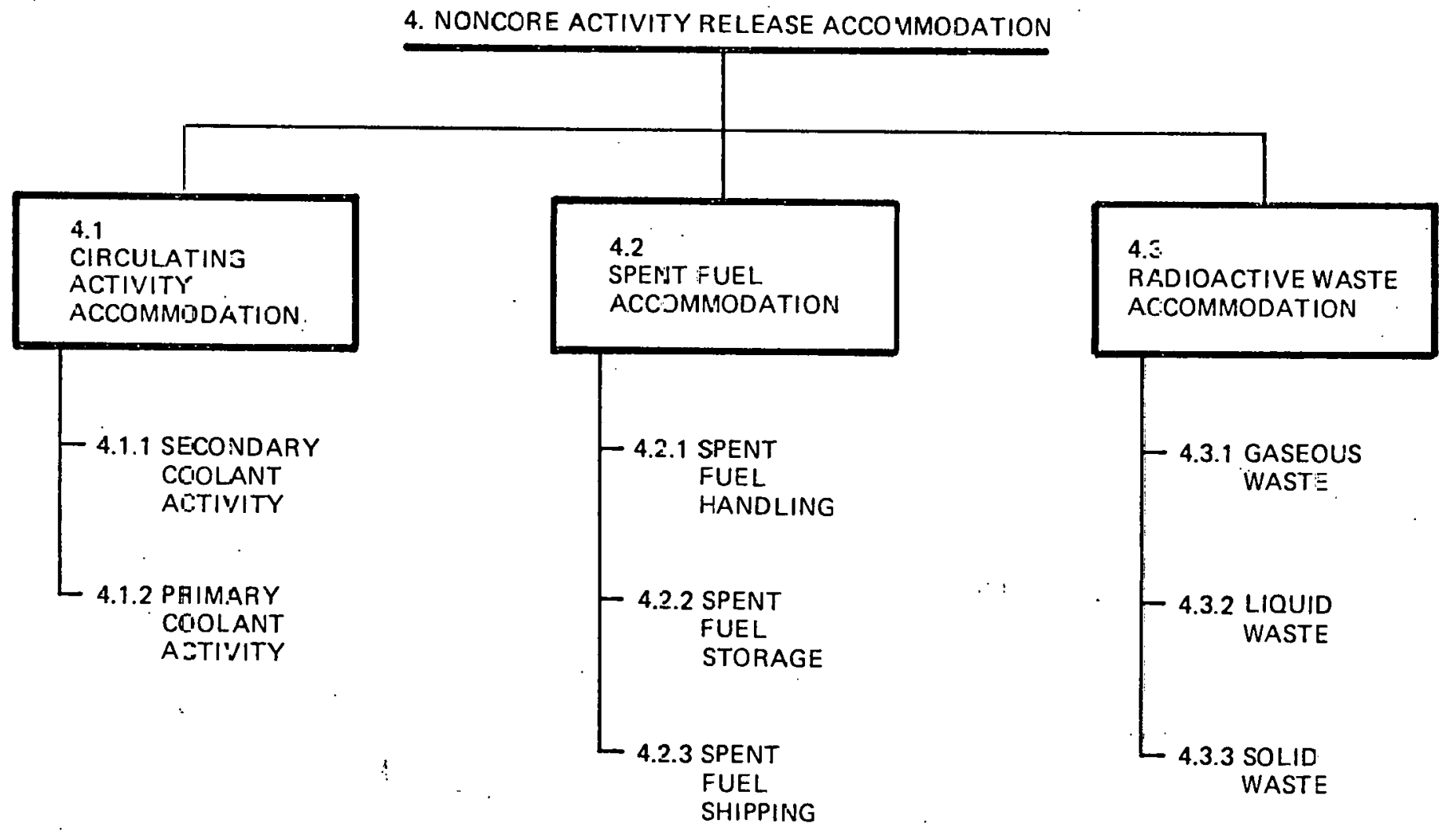

FIGURE 4-1. TASK 4 NJNCIJRE ACTIVITY RELEASE ACCOMMODATION AREA BREAKDOWN 
APPENDIX A

COMPARISON OF HTGR-AIPA RESULTS WITH THE PROPOSED SAFETY-RELIABILITY PLAN LOP APPROACH AND SAFETY CRITERION 
APPENDIX A

COMPARISON OF HTGR-AIPA RESULTS WITH SAFETY PLAN

LOP APPROACH AND SAFETY CRITERION

The purpose of this appendix is to briefly compare and correlate the results of the ongoing HTGR-AIPA safety studies with the safety approach and criterion proposed in Section 1 to this document. The most complete and recent documentation of the AIPA work may be found in Reference A-1 with relevant results summarized in the following.

\section{A.1 AIPA/LOP CORRELATION}

Early AIPA studies identified a set of representative initiating events that result in dominant risk accident sequences. In the course of studying these events, it was found that sequences leading to HTGR core heatup events appeared particularly risk significant. The Phase II risk assessment reported in Reference $A-1$, therefore, concentrates on more thorough investigations of accident events leading to and preceding an HTGR core heatup.

In terms of the magnitude and frequency of radiological consequences, a total of six release categories were identified that spanned the spectrum of 160 accident sequences and 22 plant scenarios which were studied. Table A-1 correlates each of these release categories with the five HTGR lines of protection identified in this plan. Discussion of each follows below.

\section{A.1.1 LOP 1 and 2}

LOP 1 and LOP 2 do not result in core heatup and, therefore, core heatup radalogical consequences cannot be associated with them. However, individual events identified within the AIPA event trees can be correlated with these two lines of protection as is described later in this section.

\section{A.1.2 LOP 3}

The function of LOP 3 is to demonstrate that the inherent response of the reactor system will limit core heatup, limit the radionuclide release, and prevent a threat to radionuclide containment in the event of LOP 1 and LOP 2 failure. This function may be represented in the AIPA study by release category $\mathrm{CH}-6$ which, in turn, represents those accident sequences where, even though the core cooling systems have failed, PCRV liner cooling is maintained or reestablished (within about 30 hours). Although the core is substantially damaged and significant radionuclide release from the core occurs, the cooled PCRV liner turns the core-heatup around to the extent that decomposition of the PCRV concrete does not occur. This, in turn, ensures that the core heatup does not threaten 
containment integrity due to the generation of flammable and noncondensible concrete decomposition products. The cooled liner further acts as a significant plateout and hence removal mechanism to limit radionuclide release to the containment.

\section{A.1.3 LOP 4}

The function of LOP 4 is to demonstrate that containment system integrity is maintained to delay and limit the release of radionuclides even in the event of an unrestricted core heatup resulting from failure of LOP 1 through LOP 3. This function may be associated with the AIPA study release categories 4 and 5 , which, in turn, represent accident sequences where containment failure eventually occurs due to overpressur-ization caused by the gases generated from the decomposition of PCRV concrete. Significant delay occurs (190 hours in the limiting case), however, prior to containment failure allowing significant radionuclide removal by the containment filtration system and by plateout.

\section{A. 7.4 LOP 5}

The function of LOP 5 is to demonstrate that naturally occurring and engineered external attenuation mechanisms serve to limit the quantity of radioactivity which can be transported into and through the environment even in the event of failure of the design features and systems constituting LOPs 1 through 4 . LOP 5 can be roughly correlated with AIPA study categories $\mathrm{CH}-1$ through $\mathrm{CH}-3$. These categories represent sequences where containment is not isolated or where delayed containment failure occurs with little cleanup action from HTGR systems. However, in all the accident sequences analyzed in this category, some mitigating credit is given in the AIPA study to PCRV liner cooling or containment filtration. As such the consequences calculated for $\mathrm{CH}-1$ through $\mathrm{CH}-3$ do not quite represent the limiting failures anticipated by LOP 5.

\section{A.2 SUCCESS CRITERION COMPARISON}

Figure A-1 provides a comparison of the dominant risk categories defined in the AIPA study (in terms of frequency and consequence) with the risk limit line and individual LOP criterion proposed in Section 1 of this document. Each point in Figure $A-1$ represents the median point estimate of the consequence leve ${ }^{*}$ and the total frequency of all the accident sequences having similar consequences (i.e., falling within the

\#The reader is cautioned that the consequence measure in Figure $A-1$ is in factors of 10CFR100 dose limits. AIPA results are in terms of a so-called health effects dose, which is a linear combination of the whole body gamma and inhalation doses at 2,500 meters from the plant. The combination technique places relatively more emphasis on the whole body gamma dose than the inhalation thyroid dose than does 10CFR100. Thus the consequence values in Figure $A-1$ should be considered to only roughly approximate 10CFRI00 limits applied to the low population zone. 
designated release category). $90 \%$ probability interval uncertainty bands on both frequency and consequence are identified as well.

Considering all the risk dominant events (both involving and not involving core heatup) identified in the AIPA study, it may be noted that the HTGR design studied falls well within the identified risk limit line, even including uncertainties. Considering the AIPA core heatup events (as correlated to the lines of protection in Table A-1) it may be seen that, on a median point estimate basis, the design meets the individual LOP success criterion (as identified by the darkened horizontal and vertical lines in Figure $A-1$ ). Some of the uncertainty bands may be noted, however, to fall outside the success criterion, notably: the most frequent core heatup event, $\mathrm{CH}-6$, upper limit frequency falls above the LOP 2 target; the limited core heatup event, $\mathrm{CH}-5$, frequency and consequence upper bounds lie outside the LOP 3 criterion; the unrestricted core heatup event, $\mathrm{CH}-3$, frequency bound lies above the LOP 4 criterion.

Thus it appears, at least on a cummulative accident sequence frequency basis as calculated in the AIPA study, that the success criterion identified in this safety plan are achievable, and indeed, in most cases, appear to have been achieved even allowing for uncertainties.

\section{A. 3 ACCIDENT SEQUENCE COMPARISON}

In the above the dominant AIPA cummulative risk categories are compared with the proposed safety plan success criterion. Insight into the correlation between the AIPA study results and the proposed 1 ine of protection approach can also be enhanced by considering the dominant AIPA accident sequence events as compared to the individual LOP probability targets.

Figure A-2 displays the AIPA sequence assessed as the most probable to lead to a core heatup. The sequence is initiated by a loss of main loop cooling which correlates to a LOP 1 function failure. Failure of the LOP 2 core cooling function (rather than the reactor shutdown function) by the core auxiliary cooling system (CACS) is assessed as the more likely means of causing a core heatup given LOP 1 (main loop cooling) failure. Failure of the liner cooling system leads to failure of the LOP 3 function. Finally, failure of the LOP 4 function may be correlated with the AIPA study accident path involving failure of the containment filter system and containment overpressure failure.

In Figure A-2, individual LOP frequency goals and the achieved median fault frequency for the identified accident sequence events are shown. On a median estimate basis the LOP goals appear to be achieved, with the exception of LOP 1.

In Figure $A-3$, the AIPA sequence assessed as the most probable to lead to core heatup and radionuclide containment failure is shown. This sequence is initiated by a loss of offsite power and main turbine generator trip which, in turn, causes loss of the main loop cooling LOP 1 
function. Again, failure of the LOP 2 core cooling function is identified as the more likely means of causing a core heatup; in this case, however, CACS failure is linked to the failure to restore offsite power or start the diesel generators to power essential CACS components. LOP 3 failure is caused by a failure to restore electrical power to restart the liner cooling system in 30 hours. LOP 4 failure is consequentially caused by the prolonged lack of electrical power to supply the containment filtration system.

As evidenced by Figure A-3, the cummulative target frequency for not entering LOP 5 is met for this accident sequence. However, the balance of LOP protection here is somewhat inconsistent with the LOP goals. The excessive dependence of the LOP functions on electrical power should also be noted.

\section{A. 4 REFERENCES}

A-1 "HTGR Accident Initiation and Progression Analysis Status Report," (Phase II Risk Assessment), GA-A15000, Apri1 1978. 
TABLE A-1. CORRELATION OF LOPS AND AIPA RELEASE CATEGORIES

\begin{tabular}{|c|c|c|}
\hline $\begin{array}{l}\text { Safety Plan } \\
\text { Line of Protection }\end{array}$ & $\begin{array}{c}\text { AIPA Study } \\
\text { Release Category }\end{array}$ & $\begin{array}{l}\text { Accident Category } \\
\text { Description }\end{array}$ \\
\hline 1 & NA & : \\
\hline 2 & NA & NA \\
\hline 3 & $\mathrm{CH}-6$ & $\begin{array}{l}\text { Intact containment, plateout } \\
\text { on PCRV cooled surfaces. }\end{array}$ \\
\hline 4 & $\mathrm{CH}-4$ and $\mathrm{CH}-5$ & $\begin{array}{l}\text { Delayed containment failure, } \\
\text { good plateout and filtering. }\end{array}$ \\
\hline 5 & $\begin{array}{l}\mathrm{CH}-1, \mathrm{CH}-2 \text { and } \\
\mathrm{CH}-3\end{array}$ & $\begin{array}{l}\text { Nonisolated or delayed contain- } \\
\text { ment failure, poor plateout and } \\
\text { filtering. }\end{array}$ \\
\hline
\end{tabular}




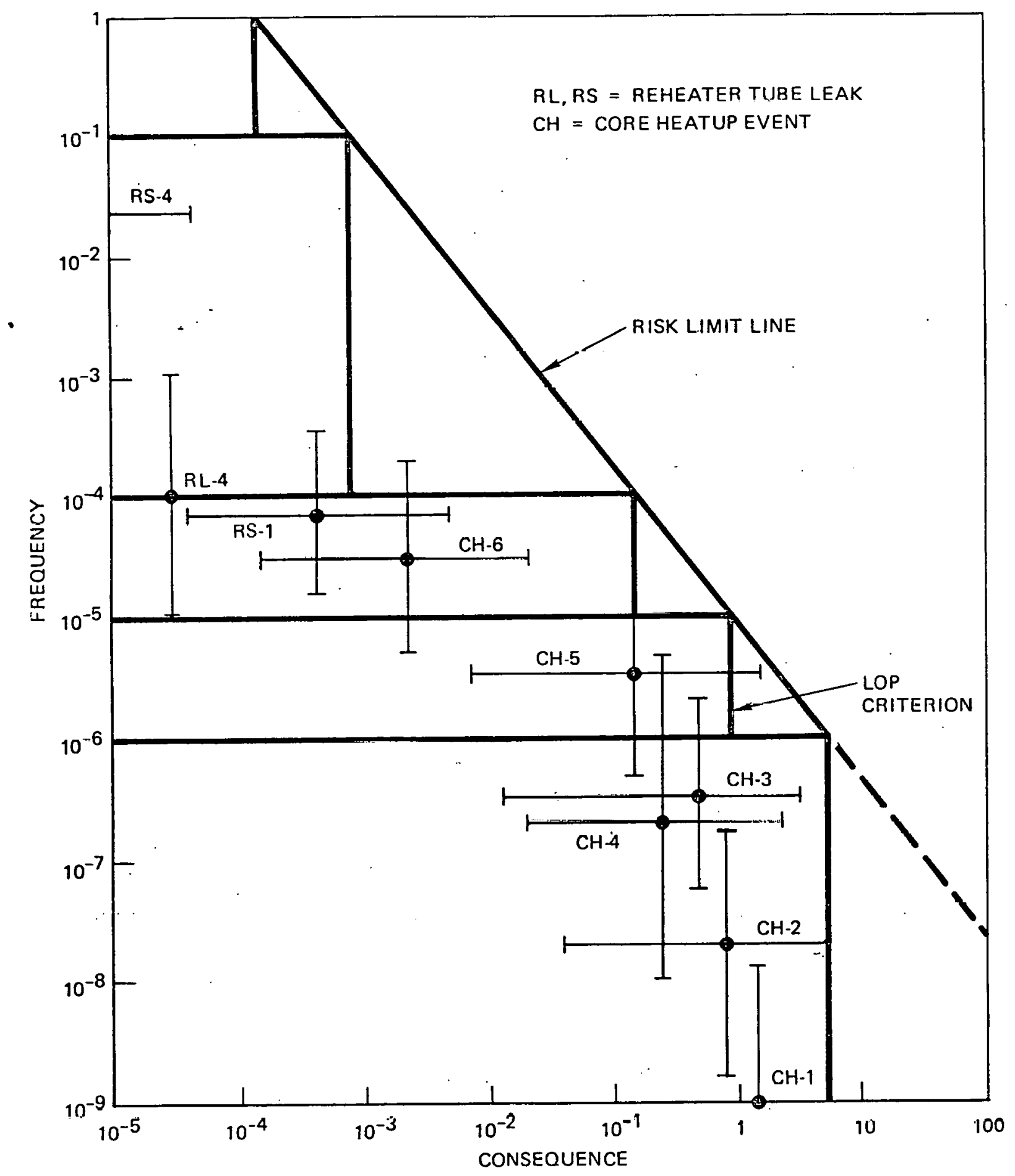

FIGURE A-1. COMPARISON OF SAFETY PLAN GOALS WITH HTGR-AIPA STUDY RESULTS 


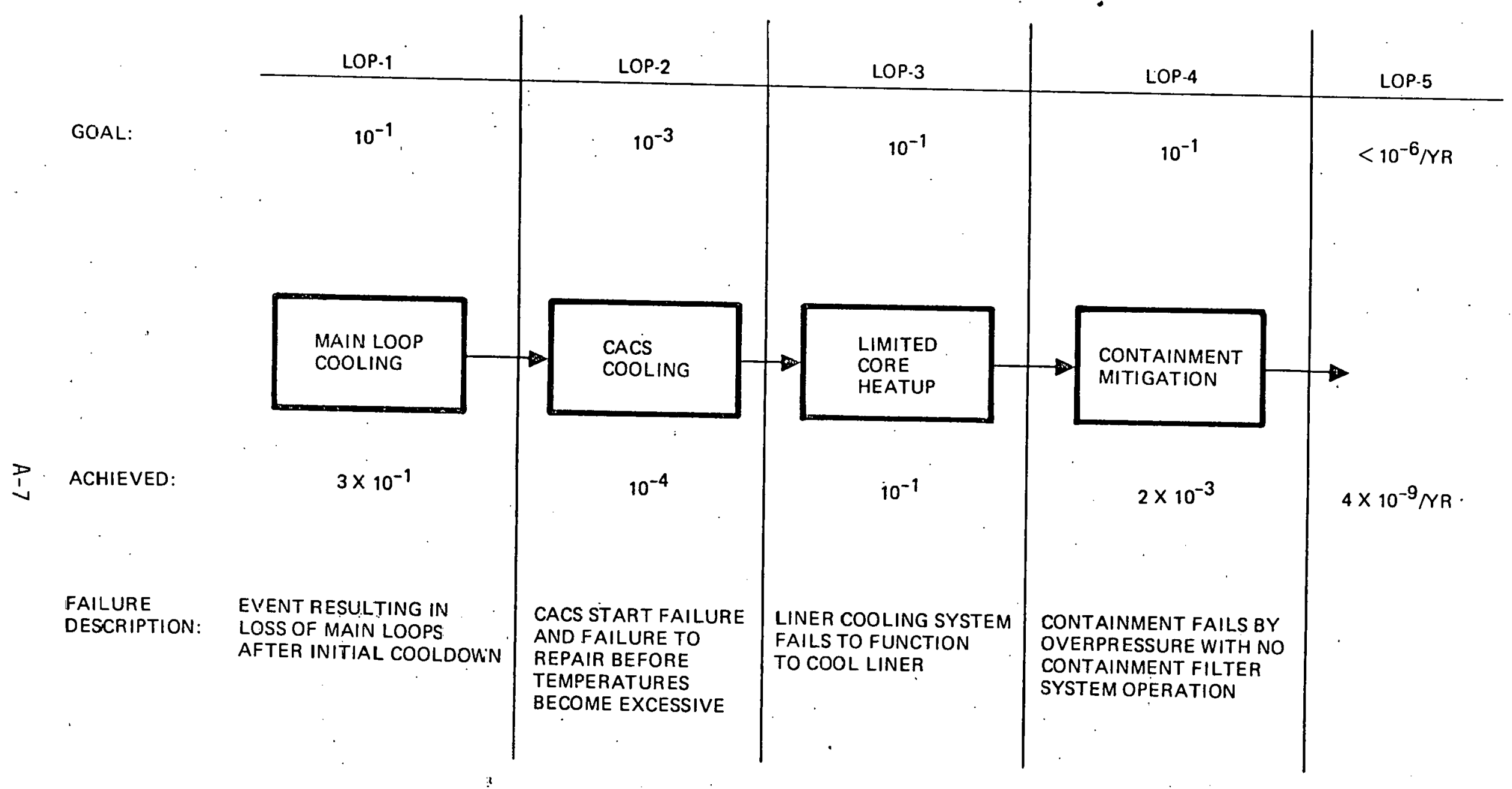

FIGURE A-2. LOSS OF MAIN LOOP COOL ING ACCIDENT SEQUENCE COMPARISON (AIPA SEQUENCE M-11-BF) 


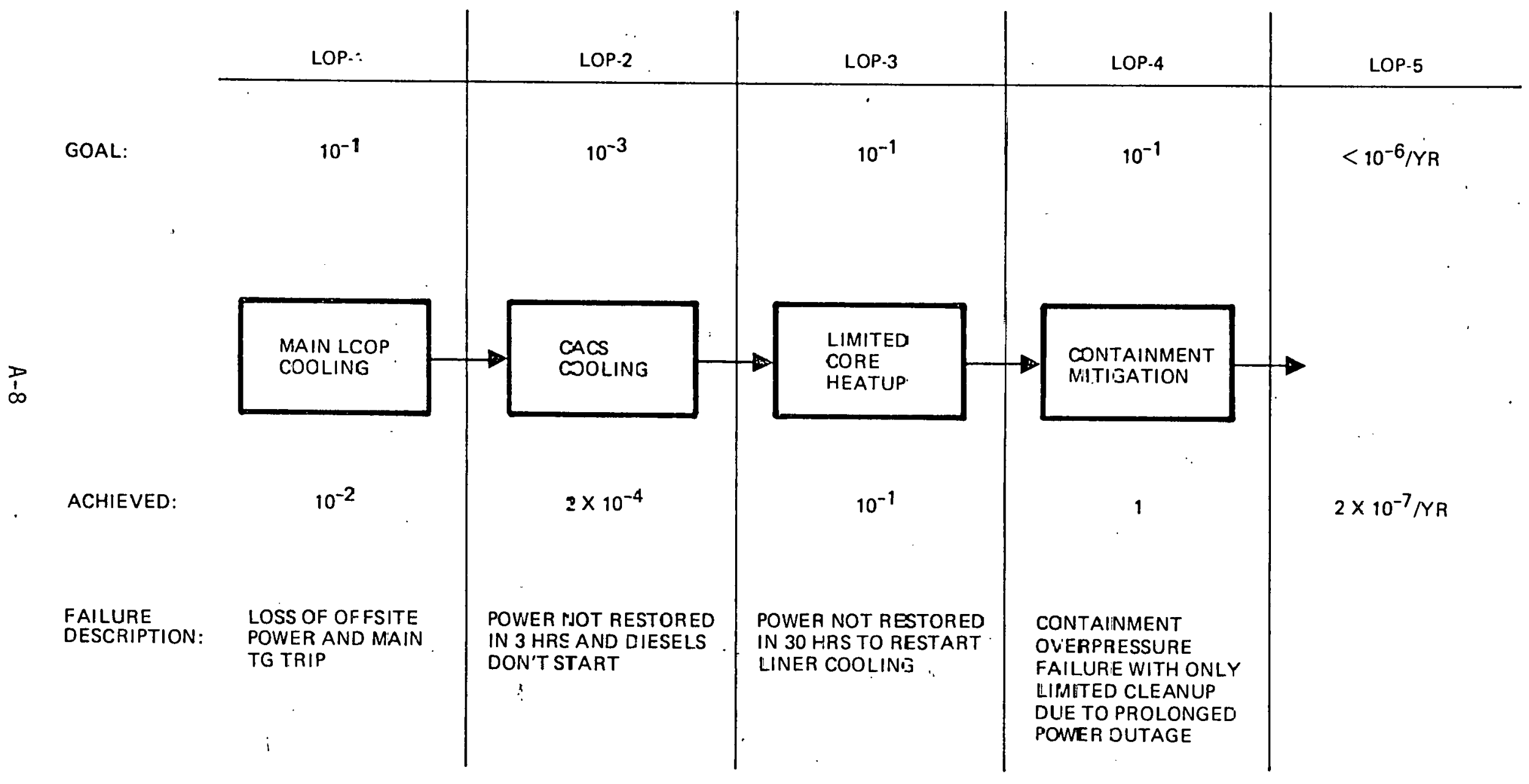

FIGURE A-3. LOSS OF OFFSITE FOWER ACCIDEP T SEQUENCE COHPARISON (AIPA SEQ̣UENCE MP-11-CL.) 